\title{
A Mapping Literature Review of Medical Cannabis Clinical Outcomes and Quality of Evidence in Approved Conditions in the USA from 2016 to 2019
}

\author{
Sebastian Jugl ${ }^{a, b} \quad$ Aimalohi Okpeku $^{a, b} \quad$ Brianna Costales $^{a, b} \quad$ Earl J. Morris $^{a, b}$ \\ Golnoosh Alipour-Haris ${ }^{a, b}$ Juan M. Hincapie-Castillo ${ }^{a, b}$ Nichole E. Stetten ${ }^{c}$ \\ Ruba Sajdeya $^{d}$ Shailina Keshwania,b Verlin Joseph ${ }^{d}$ Yahan Zhang ${ }^{a, b}$ \\ Yun Shen ${ }^{a, b}$ Lauren Adkins ${ }^{e} \quad$ Almut G. Winterstein ${ }^{a, b} \quad$ Amie Goodin $^{a, b}$ \\ aPharmaceutical Outcomes and Policy, University of Florida, Gainesville, FL, USA; ${ }^{\mathrm{b} C e n t e r}$ for Drug Evaluation and \\ Safety (CoDES), University of Florida, Gainesville, FL, USA; ' ${ }^{O}$ cccupational Therapy, University of Florida, Gainesville, FL,

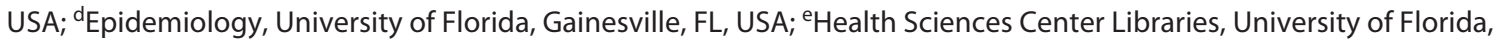 \\ Gainesville, FL, USA
}

\section{Keywords}

Medical marijuana - Cannabis - Cannabinoids · Cannabidiol · Marijuana efficacy $\cdot$ Commonly recommended conditions for marijuana treatment - Marijuana clinical outcomes

\begin{abstract}
In 2017, a National Academies of Sciences, Engineering, and Medicine (NASEM) report comprehensively evaluated the body of evidence regarding cannabis health effects through the year 2016. The objectives of this study are to identify and map the most recently (2016-2019) published literature across approved conditions for medical cannabis and to evaluate the quality of identified recent systematic reviews, published following the NASEM report. Following the literature search from 5 databases and consultation with experts, 11 conditions were identified for evidence compilation and evaluation: amyotrophic lateral sclerosis, autism, cancer, chronic noncancer pain, Crohn's disease, epilepsy, glaucoma, human immunodeficiency virus/AIDS, multiple sclerosis (MS), Parkinson's disease, and posttraumatic stress disorder. A total of 198 studies were included after screening for condition-specific relevance and after imposing the following
\end{abstract}

karger@karger.com www.karger.com/mca

Karger $\frac{1}{\%}$

GOPEN ACCESS
C 2021 The Author(s).

Published by S. Karger AG, Basel

This is an Open Access article licensed under the Creative Commons Attribution-NonCommercial-4.0 International License (CC BY-NC) (http://www.karger.com/Services/OpenAccessLicense), applicable to the online version of the article only. Usage and distribution for commercial purposes requires written permission. exclusion criteria: preclinical focus, non-English language, abstracts only, editorials/commentary, case studies/series, and non-U.S. study setting. Data extracted from studies included: study design type, outcome definition, intervention definition, sample size, study setting, and reported effect size. Few completed randomized controlled trials (RCTs) were identified. Studies classified as systematic reviews were graded using the Assessing the Methodological Quality of Systematic Reviews-2 tool to evaluate the quality of evidence. Few high-quality systematic reviews were available for most conditions, with the exceptions of MS ( 9 of 9 graded moderate/high quality; evidence for 2/9 indicating cannabis improved outcomes; evidence for $7 / 9$ indicating cannabis inconclusive), epilepsy ( 3 of 4 graded moderate/high quality; 3 indicating cannabis improved outcomes; 1 indicating cannabis inconclusive), and chronic noncancer pain (12 of 13 graded moderate/high quality; evidence for $7 / 13$ indicating cannabis improved outcomes; evidence from $6 / 7$ indicating cannabis inconclusive). Among RCTs, we identified few studies of substantial rigor and quality to contribute to the evidence base. However, there are some conditions for which significant evidence suggests that select dosage forms and routes of administration likely have favorable risk-benefit ra- 
tios (i.e., epilepsy and chronic noncancer pain). The body of evidence for medical cannabis requires more rigorous evaluation before consideration as a treatment option for many conditions, and evidence necessary to inform policy and treatment guidelines is currently insufficient for many conditions.

(c) 2021 The Author(s).

Published by S. Karger AG, Basel

\section{Introduction}

Medical cannabis is available to patients by physician order in 33 states and territories in the USA as of 2020. However, at the federal level, cannabis remains classified as a schedule I controlled substance, which limits efficacy and safety investigations [1]. Collectively, "medical cannabis" encompasses various terms used in reference to medical marijuana, cannabis-derived products from the cannabis plant (including cannabinoids), and synthetic cannabinoids (e.g., synthetic delta-9-tetrahydrocannabinol (THC) or dronabinol). States that permit physicianordered medical cannabis typically require a diagnosed medical condition that is considered qualifying by respective state law permitting its use as treatment or adjuvant. Currently, over 50 medical conditions have been granted a qualifying medical condition status by individual state laws, though there is significant variation between each state's approved conditions [2]. The most frequent medical conditions for approved medical cannabis use nationally are chronic noncancer pain, multiple sclerosis (MS) and other motor neuron disorders, epilepsy, cancer and cancer symptoms, mental health disorders (primarily anxiety disorders such as posttraumatic stress disorder [PTSD]), glaucoma, and symptoms related to irritable bowel diseases $[3,4]$.

Approximately $12.9 \%$ of Americans report past-year cannabis use, with $90.2 \%$ using for nonmedical purposes only, $6.2 \%$ for medical purposes only, and 3.6\% for both purposes [5]. The amount of medical-only cannabis users is higher in states that have enacted medical marijuana laws, where around $17 \%$ of cannabis users consumed cannabis for medical reasons in those states [6]. The most common routes of administration of cannabis use in the USA are oral/peroral (e.g., edibles), pulmonary (e.g., smoking, or vaping), and topical [7].

In 2017, the National Academies of Sciences, Engineering, and Medicine (NASEM) published a comprehensive scientific review on the effects of cannabis and cannabinoids in the treatment of medical conditions frequently cited for medical cannabis use [8]. The NASEM report included an evidence review of studies evaluating the efficacy and safety of cannabis for selected conditions based on the frequency of use, hypothesized effectiveness, and/or eligibility of the condition for medical cannabis certification across several states. The NASEM report evaluated the body of evidence published in the literature through the year 2016, and the objective of this study is to further expand this work by examining the most recently available evidence. Therefore, the objectives of this review are to (1) identify and map the most recently published clinical and scientific evidence across approved conditions for medical cannabis and (2) evaluate the quality of identified recent systematic reviews.

\section{Methods}

\section{Topic Selection}

Clinical conditions were selected based on inclusion within the NASEM report, relevance to current trends in medical cannabiseligible diagnoses, and consultation with subject matter experts and relevant stakeholders (e.g., physicians, patients, and community input). Relevant stakeholders perceived needs in research priorities, and evidence gaps as related to clinical outcomes were assessed via preliminary surveys, interviews, and open-ended discussion. Stakeholders recommended including medical conditions approved in the US state jurisdiction of the study team, in addition to emerging trends in use of medical cannabis applications based on discussion with physicians who were certified to order medical cannabis in this locale. Based on this process, the clinical conditions determined for inclusion for this review were amyotrophic lateral sclerosis (ALS), autism, cancer, chronic noncancer pain, Crohn's disease, epilepsy, glaucoma, human immunodeficiency virus (HIV)/AIDS, MS, Parkinson's disease, and PTSD.

\section{Literature Search and Identification}

The search strategy was developed in collaboration with the University of Florida Health Sciences Center Library. For this mapping review, we conducted a systematic search using the following databases: PubMed, Embase, Web of Science, the Cochrane Library, and clinicaltrials.gov. We restricted our search to studies that were published after the NASEM report's inclusion period, between May 2016 and October 2019. Search strings from the NASEM report were replicated, and additional keywords and Medical Subject Headings terms were identified in collaboration with subject matter experts and through literature cross-referencing. Since autism was the only included condition that was not evaluated by NASEM, we employed rapid review strategies and adjusted our date restriction inclusion period from the year 2000 to October 2019 for this condition. We limited our search to English language literature only. Complete search strings are available for all conditions in the see online suppl. files. (For all online suppl. material, see www.karger.com/doi/10.1159/000515069.)

\section{Literature Screening}

Screening for eligible studies was conducted in 2 phases. In each phase, publications were either classified as include, exclude,
Med Cannabis Cannabinoids 2021;4:21-42 DOI: $10.1159 / 000515069$
Jugl et al. 
or uncertain. In the first phase, for each clinical indication, one reviewer screened the identified abstracts for eligibility. Abstracts that were classified as "uncertain" were then screened by a second reviewer. If the second abstract reviewer also classified the abstract as uncertain, the publication was advanced for full-text screening. In the second phase, full-text publications were screened for eligibility for each clinical indication. Publications classified as "uncertain" during full-text screening were then screened by a second reviewer. If the publication was still classified as "uncertain" following a second full-text screening, group review and discussion were required until consensus regarding eligibility was achieved. Other discrepancies between reviewers were resolved via discussion and by a third reviewer, when necessary. Publications were included in qualitative synthesis if they were published between 27 May 2016 and 22 September 2019 and investigated the therapeutic effect, a patient or provider perspective, or utilization of medical cannabis in any form in one of the identified 11 indications or conditions. Additionally, the study had to be conducted in humans. Publications were excluded if they included only preclinical data, if the primary research was conducted exclusively outside the USA, clinical case studies, abstracts-only, letters to the editors, opinion pieces, or editorials.

\section{Data Extraction}

The study team created a standardized data extraction tool in Microsoft Excel to capture elements from all included studies. An initial pilot run with the underlying data extraction table was performed in a group setting for training purposes and to ensure consistency. Afterward, for each condition, one reviewer extracted the following data from the eligible studies into the tool: study design, study setting, cannabis intervention type, study period, inclusion and exclusion criteria, indicators for whether special populations were included (e.g., pediatrics and geriatrics), outcomes assessed, outcome definition, change in outcome, and summary of findings. Reviewers presented uncertainties in data extraction in a group discussion meeting for resolution. In instances where a single study was identified as eligible for data extraction for multiple conditions, data were independently extracted as relevant for each condition covered within the study; however, these studies were not counted more than once in overall counts of assessed studies.

\section{Quality of Evidence Assessment}

Studies that were classified as systematic reviews with or without meta-analysis were evaluated using the Assessing the Methodological Quality of Systematic Reviews-2 (AMSTAR-2) instrument. The Assessing the Methodological Quality of Systematic Reviews-2 tool was developed to grade the quality of evidence reviewed, organized, and presented within systematic reviews [9]. It consists of 16 items that evaluate the methodological quality of systematic reviews and the risk of bias via a checklist, and each item can be answered with "yes," "partial yes," "no," or "no meta-analysis conducted." Based on weaknesses in critical domains, systematic reviews are then rated as a high-, moderate-, low-, or critically low-quality review. Two reviewers for each condition conducted the evidence grading independently. Disagreements were resolved by a third reviewer, and when necessary, classifications of study design were re-evaluated. Additional reviewers examined studies when needed until the majority consensus on both study design classification and quality of evidence rating was achieved.

Mapping Review of Medical Cannabis Clinical Outcomes

\section{Evidence Synthesis}

Findings from identified studies were reported in accordance with PRISMA guidelines. Search, screening, and evaluation were conducted in accordance with systematic literature review best practices; however, the structure of this review is more appropriately classified as a mapping review to allow for its broad scope [10].

Studies in each condition were classified according to whether they assessed efficacy and/or safety outcomes. (See online suppl. Tables for outcome definitions.) Studies assessing relevant efficacy outcomes were classified into 1 of 5 categories based on the following classification scheme. Studies were classified as "outcome improved" when the condition improved following medical cannabis treatment; as "outcome worsened" when the condition worsened; as "none" when there was no significant observable change; as "inconclusive" if they specifically indicated that results were inconclusive in their results and discussion section and/or there were multiple outcomes assessed but not all reported in findings; or as "mixed" in cases where multiple outcomes were assessed, but some indicated improvement and others indicated no change or worsening. Study outcome definitions for efficacy by condition were summarized (online suppl. Table 1).

Studies reporting safety outcomes were classified into 4 different categories. Studies were classified as "worsening" when an increase in adverse events as compared to placebo, active comparator, or both groups were reported, or single-arm studies reported side effects or adverse events that might be associated with exposure; as "mixed" when different safety outcomes were assessed, but some indicated no change, while others indicated worsening; as "no change" when no significant changes in safety outcomes when measured against the comparator group were reported, or in the case of single-arm studies, studies not reporting any side effects that might be associated with exposure; or as "inconclusive" when studies specifically described results as inconclusive in the results and discussion section and/or if there were multiple outcomes assessed, but not all reported in findings were classified analogous to the efficacy outcome.

Studies that did not fit into the presented classification scheme assessed outcomes unrelated to efficacy and safety, employed a cross-sectional design, or were utilization studies, all of which were summarized separately. Cross-sectional studies were not included in the classification scheme due to their lack of longitudinal assessment, thus limiting the interpretability of findings for quantifying the evidence base in regard to efficacy and safety. Studies that were classified as "other nonsystematic reviews" (e.g., clinical, narrative, scoping, or undefined) were captured in our search strategy but were not evaluated using the classification schemes described herein.

For visualization purposes, all systematic reviews assessing safety or efficacy outcomes were compiled into an evidence map figure consisting of 5 different dimensions (Fig. 1). The bubble size is proportional to the number of included studies within each condition topic area. The bubble color represents the underlying medical condition. The $x$-axis describes the effect of cannabis in each condition. The $y$-axis represents the quality of evidence assessment score, and notations within the bubbles indicate whether the systematic reviews included meta-analysis. For a more comprehensive insight into the efficacy and safety-related findings of eligible studies, studies were finally organized by the condition-specific outcome, study design type, and directions of findings.

Med Cannabis Cannabinoids 2021;4:21-42 


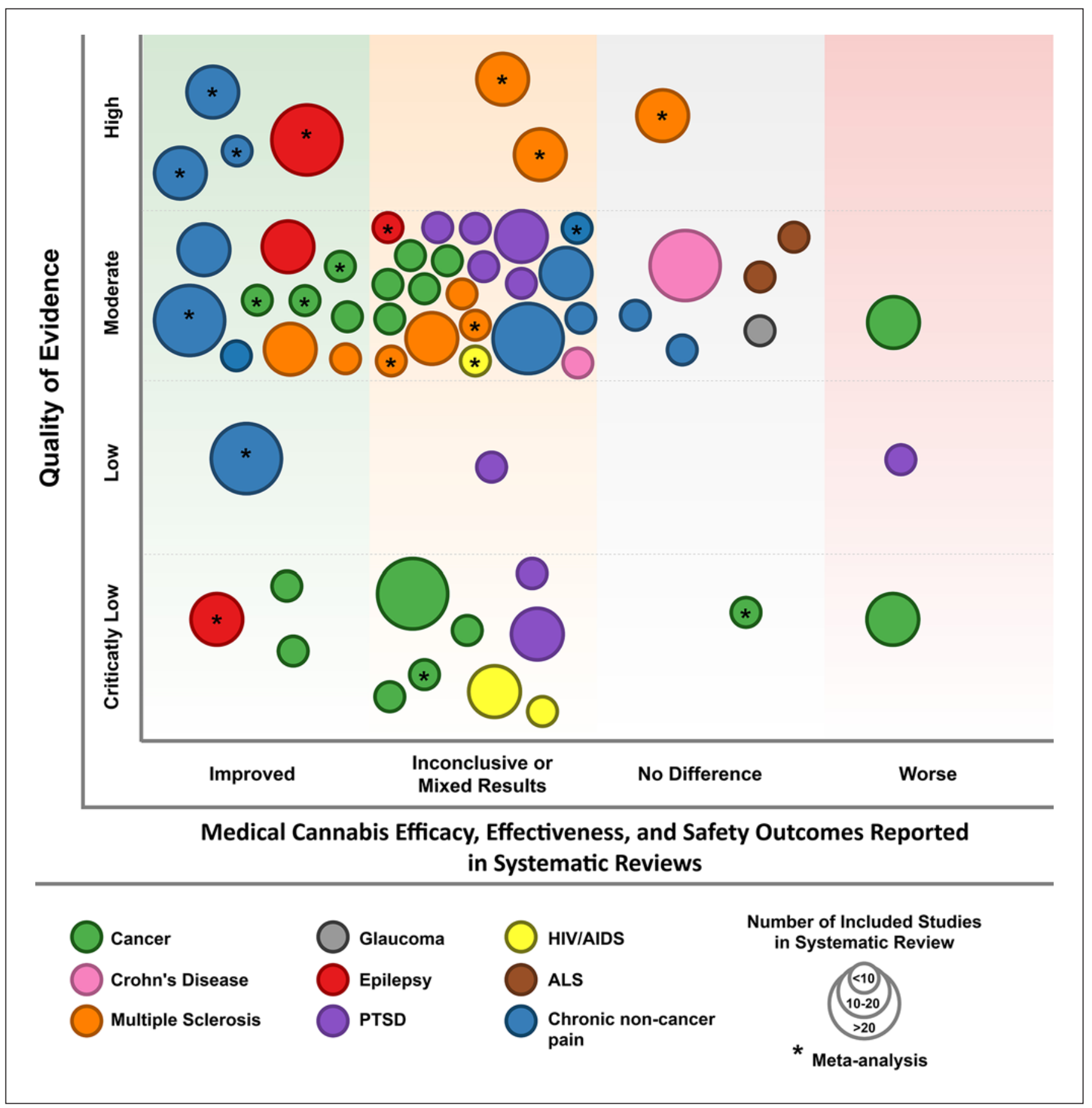

Fig. 1. Quality of evidence among systematic reviews assessing medical cannabis efficacy, effectiveness, and safety outcomes in selected conditions. MS, multiple sclerosis; ALS, amyotrophic lateral sclerosis; PTSD, posttraumatic stress disorder; HIV, human immunodeficiency virus. 


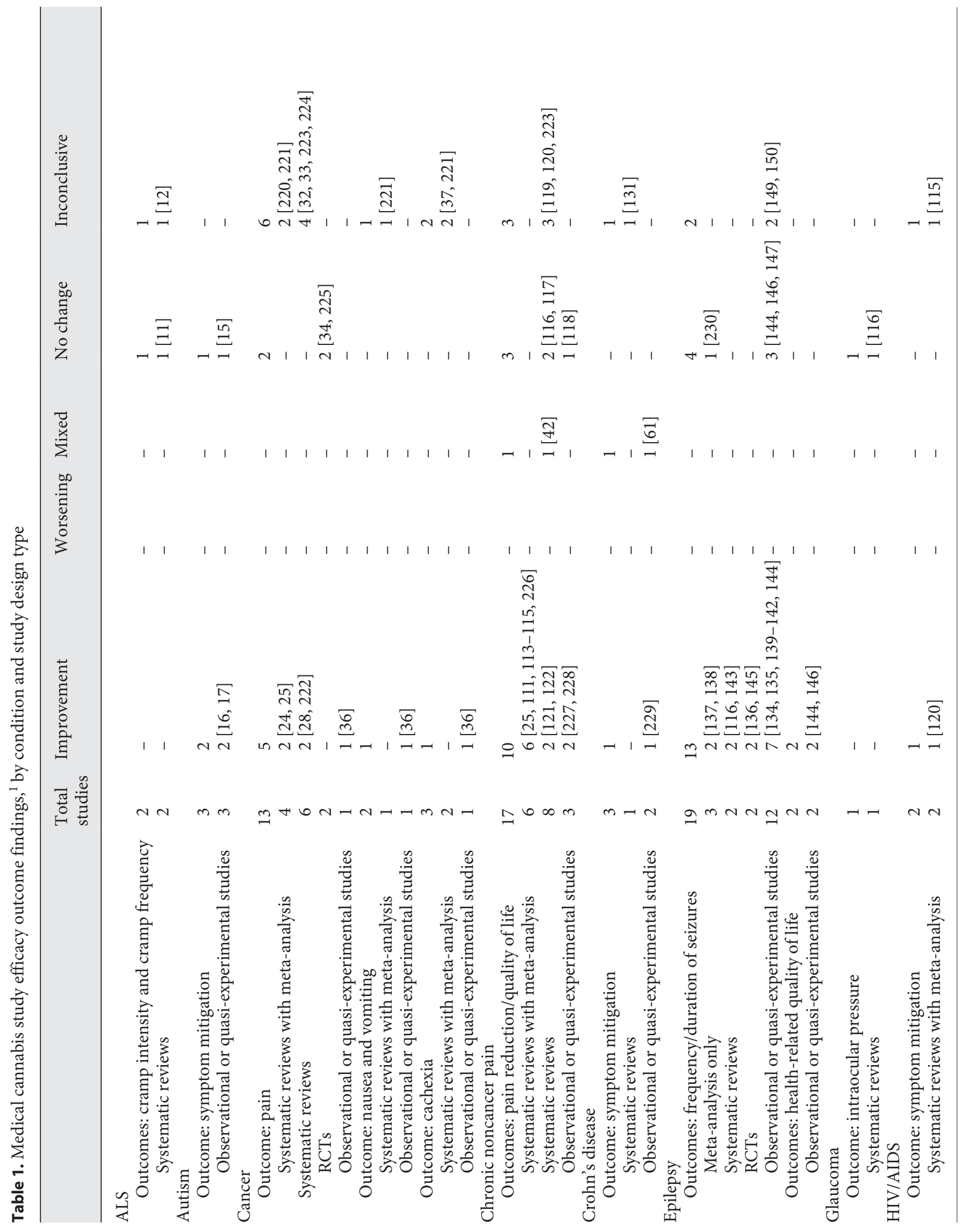




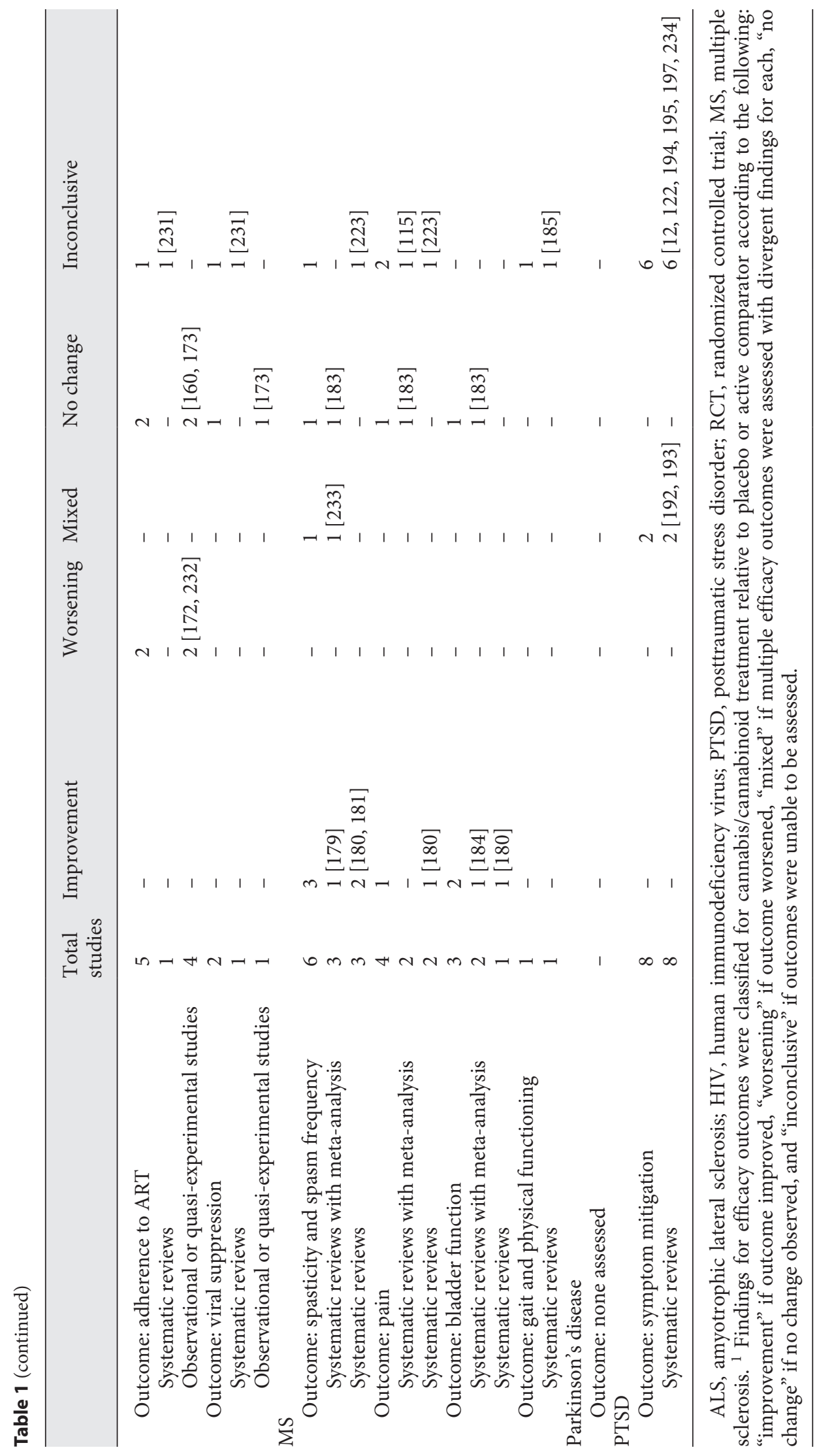




\section{Results}

A total of 15,917 studies were identified across all searched databases during the study period, where searches were conducted for each of the included clinical conditions. Following stratification by clinical condition relevance and screening for eligibility, 438 studies remained (see online suppl. materials for PRISMA flow diagrams for individual clinical conditions). We then further restricted qualitative synthesis to studies that reported primary results or systematically reviewed prior work ( $n=$ 198 ), meaning that 240 studies were narrative reviews or other types of nonsystematic reviews. Table 1 summarizes efficacy findings as stratified by study design type and condition, and Table 2 summarizes the same for safety findings. Table 3 summarizes cannabis agents administered or observed in randomized controlled trials (RCTs) and observational studies by agent and route of administration for each condition. Below, we summarize condition-specific findings.

\section{Amyotrophic Lateral Sclerosis}

As depicted in the flow diagrams (online suppl. files), the use of medical cannabis in patients with ALS was investigated in 9 eligible publications. Among those were 2 systematic reviews without meta-analysis, 2 observational/quasi-experimental studies, and 5 other types of reviews. Of all studies investigating medical cannabis and ALS, 2 studies used cramp intensity/frequency as the primary outcome $[11,12]$ and 2 investigated other outcomes or used a cross-sectional design [13, 14]. Among those studies that investigated cramp intensity/frequency, one indicated no change [11] and one study indicated inconclusive findings [11, 12]. (More detailed information about each study type and summary of findings can be found in Tables 1 and 2 and in the online suppl. files.) Other outcomes assessed in this condition included an examination of trajectories of ALS cases [13], and one cross-sectional study assessed patient characteristics in a dispensary and dispensary staff recommendations [14].

\section{Autism}

Medical cannabis in patients with autism was investigated in 17 eligible publications. Among those were one systematic review with meta-analysis, 8 observational/ quasi-experimental studies, and 8 other types of reviews. Of all studies investigating medical cannabis and autism, 3 studies used symptom mitigation (see online suppl. Table 1 for outcome definitions) as the primary outcome [15-17] and 6 investigated other outcomes or used a cross-sectional design [18-23]. The latter studies and other types of reviews are summarized in the online suppl. files. Among those studies that investigated symptom mitigation, 2 indicated an improvement $[16,17]$ and one study indicated no change in symptoms [15]. Other outcomes assessed in this condition were assessed in 6 studies, of which one used a cross-sectional study design. Among those outcomes that were assessed by more than 1 study, 2 studies assessed the brain activity in response to $\mathrm{CBD}$ with functional magnetic resonance imaging and magnetic resonance spectroscopy $[22,23]$.

Cancer

Medical cannabis in patients with cancer was investigated in 138 eligible publications. Among those were 6 systematic reviews with meta-analysis, 10 systematic reviews without meta-analysis, 4 RCTs, 31 observational/ quasi-experimental studies, and 86 other types of reviews. Of all studies investigating medical cannabis and cancer, 13 studies investigated cancer-related pain reduction as the primary outcome [24-36]; 2 studies investigated cancer-related nausea and vomiting [27, 36]; 3 studies investigated weight change, appetite increase, or caloric intake $[27,37] ; 17$ studies investigated safety outcomes [24, 26$32,34-36,38-43]$; and 31 studies investigated other outcomes or used a cross-sectional design [3, 44-73]. Among studies that investigated cancer-related pain, 5 indicated an improvement $[24,25,28,29,36], 2$ studies indicated no change $[34,35]$, and 6 were inconclusive $[26,27,30$, $32,74,75]$. Among studies that investigated cancer-related nausea and vomiting, one indicated an improvement [36] and one was inconclusive [27]. In studies that investigated weight change, appetite increase, or caloric intake, one indicated an improvement [36] and 2 were inconclusive $[27,37]$. Of the 17 studies assessing safety outcomes of medical cannabis in cancer patients, 11 studies indicated worsening $[24,26,28,29,34-36,38-40,43]$, one indicated mixed findings [41], and 5 studies were inconclusive $[27,30,32,42,74]$. For 2 RCTs, results are still pending at this time $[76,77]$. Other outcomes assessed in this condition were assessed in 31 studies, of which 24 used a cross-sectional study design. Among those outcomes that were assessed by more than one study, 10 studies investigated patients or provider perceptions of cannabis benefits and side effects $[47,52,53,56,60,62$, 64, 67-69] and 7 investigated patterns of cannabis consumption $[48,49,55,57,63,71,72]$.

Med Cannabis Cannabinoids 2021;4:21-42 DOI: $10.1159 / 000515069$ 


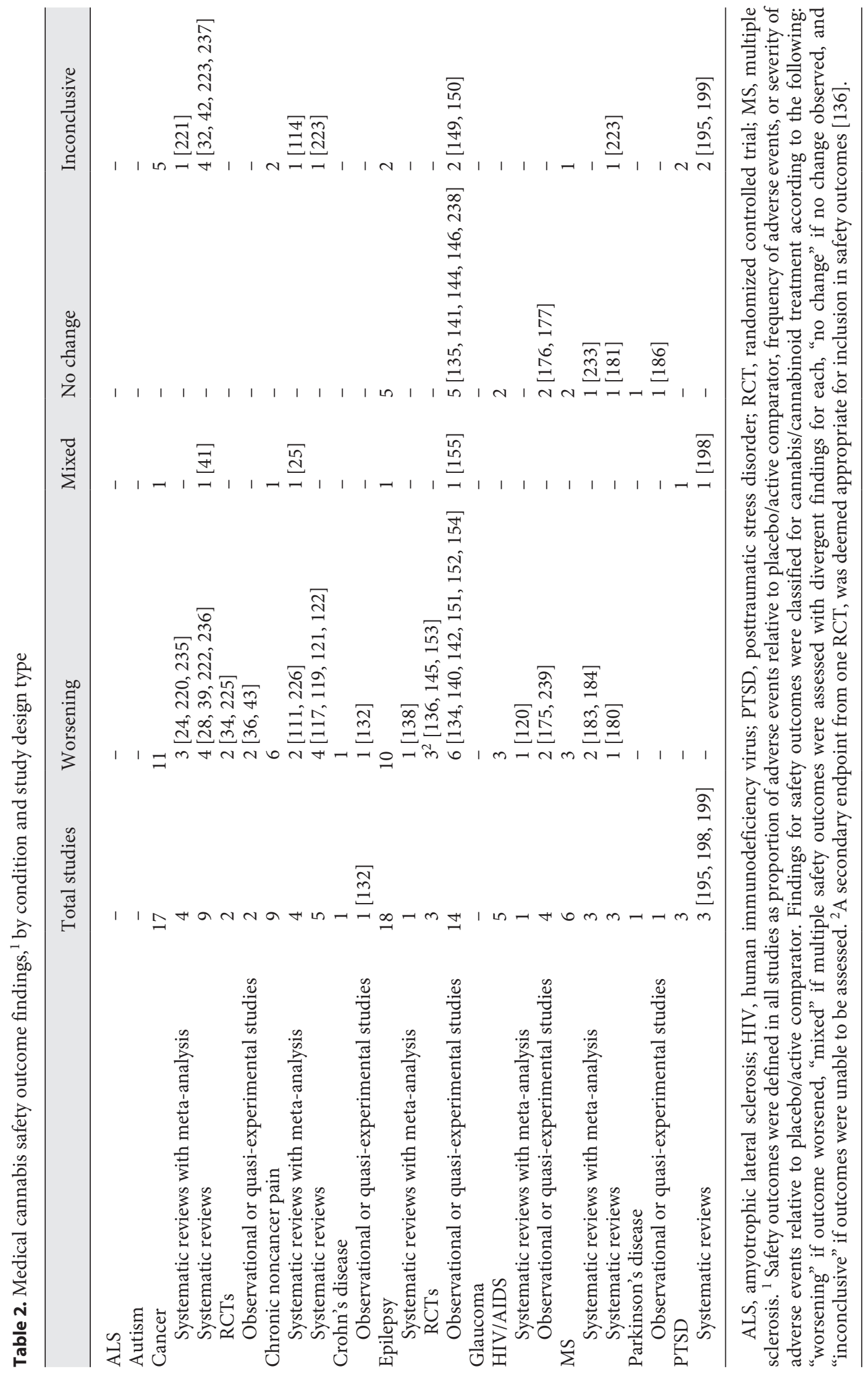




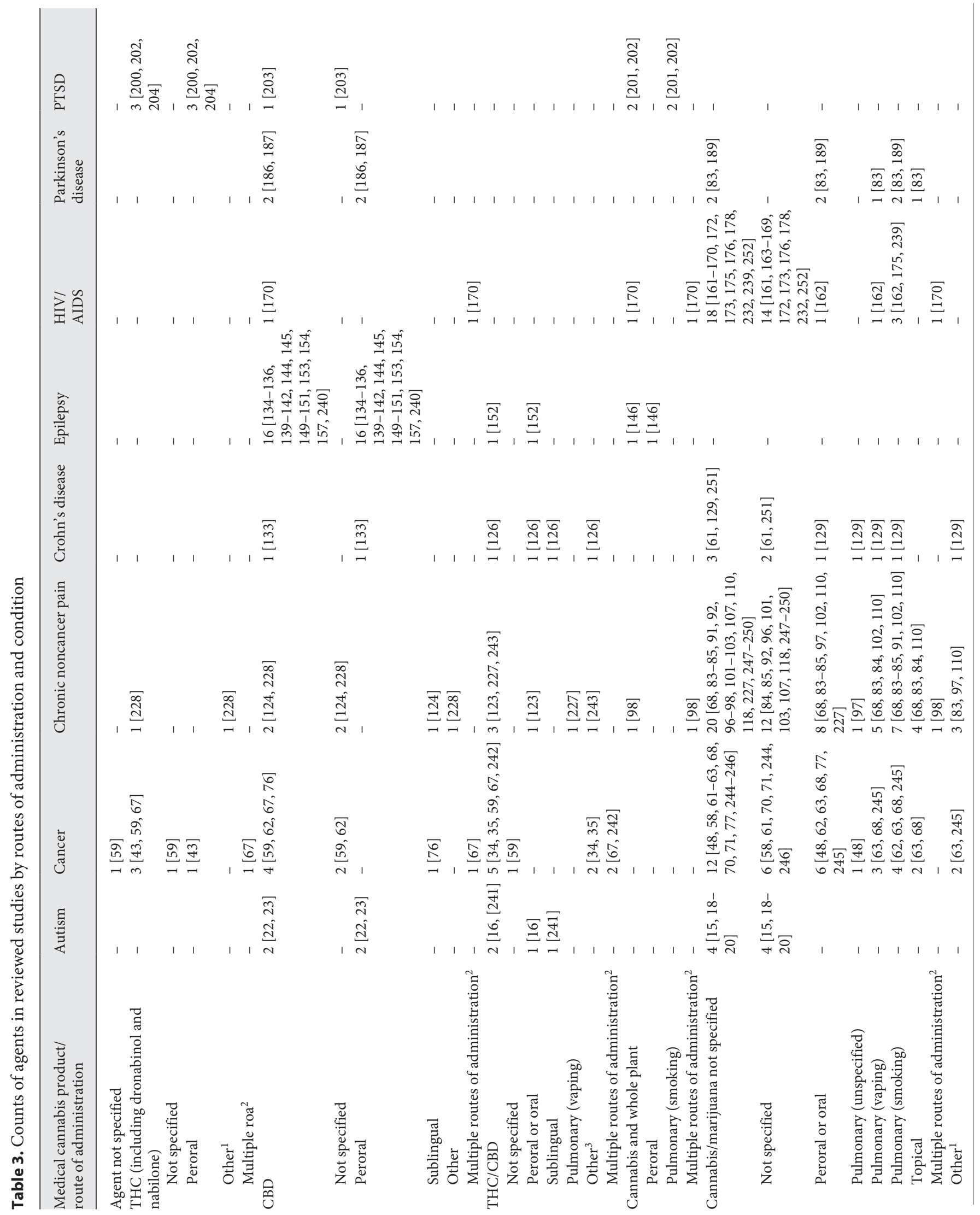




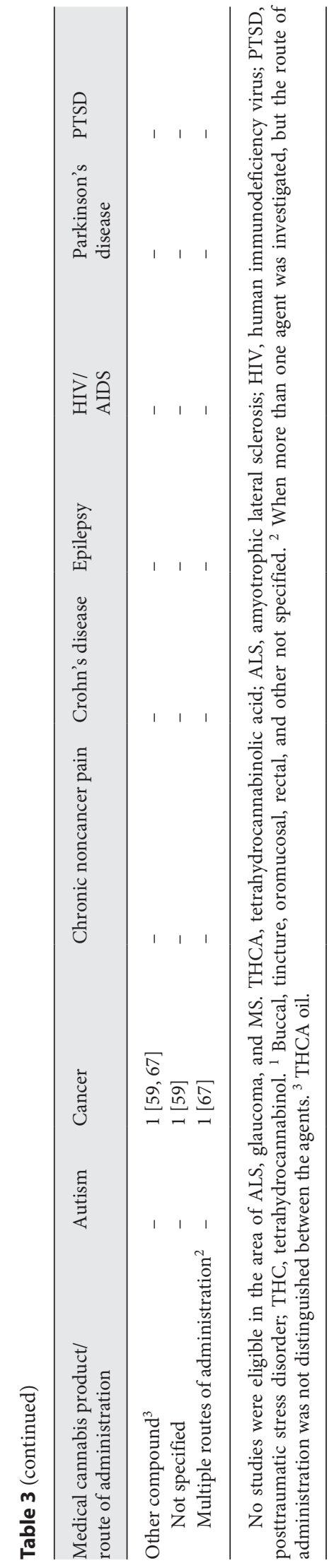

\section{Chronic Noncancer Pain}

Medical cannabis in patients with chronic noncancer pain was investigated in 120 publications. Among those were 8 systematic reviews with meta-analysis, 8 systematic reviews without meta-analysis, 3 RCTs, 36 observational/quasi-experimental studies, and 63 other types of reviews. Of all studies investigating medical cannabis and chronic noncancer pain, 17 studies investigated pain reduction or quality of life as the primary outcome, 9 studies investigated safety outcomes, and 35 investigated other outcomes or used a cross-sectional design $[14,68$, $78-$ 110]. Among those studies that investigated pain reduction or quality of life, 10 indicated an improvement $[25,111-115]$, one study indicated mixed findings [42], 3 studies indicated no change [116-118], and 3 were inconclusive $[30,119,120]$. Of the 9 studies investigating safety outcomes of medical cannabis in patients with chronic noncancer pain, 6 studies indicated a worsening [111, $112,117,119,121,122], 1$ indicated mixed findings [25], and 2 were inconclusive $[30,114]$. For 3 RCTs, results are still pending (see online suppl. Table 2) [123-125]. Thirty-five eligible studies, including 27 cross-sectional studies, investigated other outcomes. Among those outcomes that were assessed by more than 1 study, 9 studies investigated patients or provider perceptions of cannabis benefits and side effects $[84,85,88,92,100,102,103,106$, 107], 8 studies investigated different relationships between cannabis use and opioid use $[79,81,87,96,101$, $105,108,109], 6$ studies investigated cannabis use patterns $[78,82,83,90,97,110], 2$ examined consumer characteristics $[89,93]$, and 2 explored reasons for medical cannabis use $[68,99]$.

\section{Crohn's Disease}

Twenty-five publications investigated medical cannabis in patients with Crohn's disease. Among those were 2 systematic reviews without meta-analysis, 1 RCT, and 8 observational/quasi-experimental studies. Of all studies investigating medical cannabis in patients with Crohn's disease, 3 studies investigated symptom mitigation as the primary outcome, 1 study investigated safety outcomes, and 6 investigated other outcomes or used a cross-sectional design $[14,116,126-129]$. In studies that investigated symptom mitigation, 1 study indicated an improvement [130], 1 study indicated mixed findings [61], and one was inconclusive [131]. Safety outcomes were reported by one study, which indicated worsening safety outcomes [132]. The RCT has recently been withdrawn due to inadequate funding [133]. Six eligible studies, including 3 cross-sectional studies, investigated other outcomes. 
Outcomes that were assessed by more than one study included patient perceptions of cannabis benefits and side effects, which was assessed by 2 studies [127, 128], and cannabis use patterns, which was investigated by 2 studies $[126,129]$.

\section{Epilepsy}

Medical cannabis in patients with epilepsy was investigated in 72 eligible publications. Among those were 3 systematic reviews with meta-analysis, 2 systematic reviews without meta-analysis, 3 RCTs, 17 observational/ quasi-experimental studies, and 47 other types of reviews. Of all studies investigating medical cannabis and epilepsy, 19 studies investigated the effect on seizures (i.e., reductions in number of seizures and seizure frequency) as the primary outcome, 2 studies assessed health-related quality of life, 18 studies investigated safety outcomes, and 3 studies investigated other outcomes or used a crosssectional design. Among those studies that investigated the effect on seizures as outcomes, 13 studies indicated an improvement [116, 134-145], 4 studies indicated no change [144, 146-148], and 2 studies were inconclusive $[149,150]$. In those studies that investigated health-related quality of life or quality of life as the primary outcome, both studies indicated an improvement $[144,146]$ and one study indicated no change [146]. Among those 18 studies that investigated safety outcomes, 10 studies indicated worsening $[134,136,138,140,142,145,151-154]$, 1 indicated mixed findings [155], 5 indicated no change $[135,141,144,156]$, and 2 were inconclusive $[149,150]$. Three eligible studies, including 1 cross-sectional study, investigated other outcomes. One study assessed potential pharmacokinetic interactions [157], one investigated perception about cannabis use and benefits [158], and the third assessed doses of cannabidiol [116].

\section{Glaucoma}

Medical cannabis in patients with glaucoma was investigated in 14 eligible publications, including one systematic review without meta-analysis and one book section. (Detailed information about the latter and the 12 other types of reviews can be found in the online suppl. files.) Of all studies, one investigated the effect of medical cannabis on intraocular pressure, and this study indicated no change in the outcome [116].

\section{Human Immunodeficiency Virus/AIDS}

Medical cannabis in patients with HIV/AIDS was investigated in 25 eligible publications, among those were 3 systematic reviews with meta-analysis, 19 observational/ quasi-experimental studies, and 3 other types of reviews. Of all studies within this section, 2 studies investigated symptom mitigation (see online suppl. material) as the primary outcome, 4 studies investigated the effect on adherence to antiretroviral therapy, 2 studies investigated the effect on viral suppression, 5 studies investigated safety outcomes, and 12 studies investigated other outcomes or used a cross-sectional design [159-170]. Among the 2 studies that investigated symptom mitigation, one indicated an improvement [120] and one was inconclusive [115]. Among the 5 studies examining the effect of cannabis use on adherence to antiretroviral therapy, 2 indicated worsening $[171,172], 2$ reported no change [160, 173], and 1 reported inconclusive findings [174]. One study examining the effect on viral suppression indicated no change [173], and 1 study indicated inconclusive findings [174]. Of the 5 studies investigating safety outcomes, 3 studies indicated worsening $[120,175,176]$ and 2 studies indicated no change $[176,177]$. Twelve eligible studies, including 6 cross-sectional studies, investigated other outcomes. Among those outcomes that were assessed by more than one study, 5 studies assessed aspects of HIV care continuum measures $[160-163,168]$ and 2 studies assessed the prevalence and correlates of substance use $[165,178]$.

\section{Multiple Sclerosis}

Medical cannabis in patients with MS or related motor neuron disorders was investigated in 25 eligible publications. Among those were 5 systematic reviews with metaanalysis, 4 systematic reviews without meta-analysis, and 16 other types of reviews. Of all studies within this section, 6 studies investigated spasticity and spasm as the primary outcome, 4 studies investigated efficacy on MSrelated pain, 3 studies investigated bladder function, 1 study examined the effect on gait function, and 6 studies investigated safety outcomes. (More information about the 17 other types of reviews can be found in the online suppl. files.) Among the 6 studies investigating spasticity and spasm, 3 indicated an improvement [179-181], one indicated mixed findings [182], one study reported no change [183], and one was inconclusive [30]. Among the 4 studies examining MS-related pain, one indicated improvement [180], one reported no change [183], and 2 reported inconclusive findings $[30,115]$. Of studies examining the effect on bladder function, 2 indicated improvement $[180,184]$ and one reported no change [183]. One study investigating gait function reported inconclusive findings [185]. In studies investigating safety outcomes, 3 studies indicated worsening [180, 183, 184], 2 
studies indicated no change $[181,182]$, and 1 study reported inconclusive findings [30].

\section{Parkinson's Disease}

Medical cannabis in patients with Parkinson's disease was investigated in 17 eligible publications. Among those were one RCT and 4 observational/quasi-experimental studies. Of all studies, one study investigated the effect of medical cannabis on safety outcomes and indicated no change in the outcome [186]. For one RCT, results are still forthcoming [187]. Other outcomes were investigated by 3 cross-sectional studies. All of these studies investigated physicians or patient expectations or perceived benefits of cannabis on Parkinson's disease-related symptoms $[83,188,189]$. (More information about the studies that assessed other outcomes and the 12 other types of reviews can be found in the online suppl. files.)

\section{Posttraumatic Stress Disorder}

Medical cannabis in patients with PTSD was investigated in 50 eligible publications. Among those were 10 systematic reviews without meta-analysis, 5 RCTs, 3 observational/quasi-experimental studies, and 31 other types of reviews. Of all studies investigating medical cannabis in patients with PTSD, 8 studies investigated symptom mitigation (e.g., sleep disturbances, dissociative reactions or flashbacks, and hyperarousal) as the primary outcome, 3 studies investigated safety outcomes, and 3 assessed other outcomes or used a cross-sectional design $[14,190,191]$. Among those studies that investigated symptom mitigation, 2 indicated mixed findings [192, 193] and 6 were inconclusive [12, 122, 194-197]. One study investigating safety outcomes indicated mixed findings [198], and 2 studies reported inconclusive findings $[195,199]$. Among those 5 RCTs, 1 study has been terminated, 2 were completed, but publications were not available at the time of literature search, and for 2, results are still pending. For 5 RCTs, results are still pending [200-204]. Three eligible studies, including 2 cross-sectional studies, investigated other outcomes. Two of 3 investigated cannabis dispensary staff or healthcare provider practices $[14,191]$ and 1 study investigated cannabis use patterns and associated problems [190].

\section{Cannabis Agents}

The vast majority of RCTs and observational studies (including cross-sectional studies) that investigated the safety or efficacy of cannabis did not further specify the type of cannabis product that was investigated. A specific route of administration was also often not reported.
Among those publications that specified the cannabis product, $\mathrm{CBD}$ was the most frequent investigated agent and mostly for investigations related to epilepsy or other seizure disorders. Whole plant cannabis was the least investigated drug. With respect to route of administration, studies investigating THC, CBD, or THC and CBD combinations typically employed oral/peroral, buccal, or sublingual administration. This is in contrast to those studies assessing unspecified agents, in which pulmonary and oral/peroral administrations were most common. We encountered only one study that assessed minor cannabinoids, namely, tetrahydrocannabinolic acid.

\section{Evidence Map}

The majority of identified systematic reviews were conducted on the topic areas of chronic noncancer pain, cancer, MS, epilepsy, and PTSD. The evidence map includes indications for conditions that were determined to have scarce recent evidence available. The quality of evidence varied widely among all eligible systematic reviews and differed between each condition. Reviews graded as either critically low or low quality, indicating serious risks of biases and/or methodological limitations, were mainly conducted in the areas of cancer, PTSD, and HIV/AIDS. Moderate-quality systematic reviews were represented in all conditions. Only the areas of chronic noncancer pain, epilepsy, and MS included systematic reviews graded as high quality. In terms of safety and efficacy outcomes, only a few systematic reviews in the area of ALS, cancer, chronic noncancer pain, Crohn's disease, glaucoma, and MS indicated worsening or no difference. The majority of included reviews reported inconclusive or mixed results, and only publications in the area of chronic noncancer pain, cancer, epilepsy, and MS reported improved outcomes. Furthermore, among high-quality reviews, only chronic noncancer pain and epilepsy reported improved outcomes (see Fig. 1).

\section{Discussion}

Referring to the 11 investigated conditions, the NASEM report in 2017 concluded that there is conclusive or substantial evidence for cannabis in treating chronic noncancer pain, chemotherapy-induced nausea and vomiting (oral cannabinoids), and MS spasticity symptoms (via oral cannabinoids). In addition, limited evidence was reported for the efficacy of cannabis and cannabinoids for the purposes of increasing appetite and decreasing weight loss in patients with HIV/AIDS, im-
Med Cannabis Cannabinoids 2021;4:21-42 DOI: $10.1159 / 000515069$
Jugl et al. 
proving clinician measures of MS spasticity symptoms (specifically, via oral cannabinoids), and improving symptoms of PTSD (specifically, with nabilone). NASEM also concluded that limited evidence was available that cannabis and cannabinoids were ineffective in improving intraocular pressure associated with glaucoma (specifically via cannabinoids). Furthermore, insufficient or no evidence existed to support or refute the effectiveness of cannabis or cannabinoids for a majority of examined indications. Those indications included cancer (cannabinoids), cancer-associated anorexia-cachexia syndrome and anorexia nervosa (cannabinoids), symptoms of irritable bowel syndrome (dronabinol), epilepsy (cannabinoids), symptoms associated with ALS, or Parkinson's disease-related symptoms or levodopa-induced dyskinesia (cannabinoids).

In the 4 years since the NASEM report, much has been published in the clinical and scientific literature regarding the safety and efficacy of cannabis and cannabinoids, but we identified few recent studies conducted within US populations and were of substantial rigor and quality to move the evidence base forward for many clinical conditions. In fact, across all condition topic areas, the most frequently identified study design was clinical/narrative review with a nonsystematic approach, and these reviews only recounted and compiled previous RCT and observational study findings. Many other identified studies, particularly observational studies, also had significant limitations when assessing the safety and efficacy of cannabis that potentially affected validity. Detailed information about the history of cannabis use, other substance use, concomitant medications, comorbidities, types of cannabis product (THC, $\mathrm{CBD}, \mathrm{THC} / \mathrm{CBD}$, and whole plant), route of administration, and dosage was not captured in the majority of observational studies due to unavailable data or limited subject knowledge. Thus, confounding was a recurring threat to validity in many identified studies. Several observational studies, for example, suggest that cancer patients using medical cannabis tend to have more severe symptoms than those who did not consume medical or recreational cannabis $[57,60,71]$. However, it is unclear if cannabis is contributing to more severe symptoms or if the presence of severe symptoms prompted increases in cannabis utilization. In addition, patientreported outcomes and behaviors may be more susceptible to recall bias and/or inaccurate reporting of dosage, duration, and frequency of use $[205,206]$. Patients also might not report nonmedical cannabis use due to perceived social norms.

Mapping Review of Medical Cannabis Clinical Outcomes

\section{Quality of Evidence}

Our assessment of the quality of systematic reviews determined that high-quality systematic reviews were conducted only among the conditions of chronic noncancer pain, epilepsy, and MS. In the area of chronic noncancer pain, the most recent systematic reviews are in alignment with findings of the NASEM report, which reported substantial evidence for the use of cannabis as a treatment for chronic pain in adults.

In the area of epilepsy, one recently published highquality systematic review included several newly published RCTs focusing on pediatrics and found significantly reduced seizure frequency with adjunctive CBD use in pediatric drug-resistant Dravet and Lennox-Gastaut syndromes, aligning with the FDA approval of Epidiolex. High-quality systematic reviews in the field of MS did not include any RCT results following the publication of the NASEM report and are, therefore, not expanding the evidence base.

Only 7 systematic reviews were graded as high quality, whereas almost one-third were graded as low- or critically low-quality systematic reviews. Common reasons for being rated as a moderate- or low-quality review were due to the absence of a prior established protocol, lack of a comprehensive literature search strategy, failing to report the source of funding of included studies, missing an adequate detailed description of excluded studies, inadequate accounting for the risk of bias assessment within result interpretation and discussion, absence of adequate discussion of heterogeneity, and absence of a quantitative synthesis or meta-analysis. In addition to these limitations, many identified systematic reviews also consisted of few RCTs.

Despite the limited evidence available from recent high-quality systematic reviews, it is promising that we identified 12 RCTs with registered protocols and trial registrations. The studies are covering the field of Crohn's disease, chronic noncancer pain, cancer, Parkinson's disease, and PTSD [76, 77, 123-125, 133, 187, 200-204], and 2 of them have recently been withdrawn or terminated $[133,202]$. However, the remaining 10 RCTs have the potential to expand the evidence base. In addition, our review identified many studies that reported an increase in adverse events relative to placebo or an active comparator, which was consistent across most of the assessed medical conditions. Nevertheless, the vast majority of the reviewed studies reported that adverse event severity ranged from mild to moderate, and most adverse events were reversible with dose reduction or discontinuation. Medical cannabis was often referred to as "generally well

Med Cannabis Cannabinoids 2021;4:21-42 DOI: 10.1159/000515069 
tolerated." However, information about long-term safety outcomes was scarce.

\section{Gaps in Literature}

We identified several persistent gaps in the literature during this review. Recent observational studies often lacked specific information about the route of administration, dosage, frequency, and cannabis product used. Clinical trials were mainly limited to peroral, oral, or sublingual administration and represented few formulations of available cannabis products. Studies investigating whole-plant cannabis products are needed to better understand the risks and benefits of cannabis in real-world settings as patients receiving medical cannabis in practice are typically receiving whole-plant products. In order to provide valuable information about the effectiveness and safety of medical cannabis, real-world studies must define cannabis products, the route of administration, and dosage precisely. In addition, it is unclear whether or not standardized products provided in RCTs are comparable to those products offered by dispensaries, where consistency in product dosing, concentrations, and even routes of administration offered are not necessarily guaranteed and are subject to variations in state regulations [207]. Furthermore, there remain other questions about the generalizability of existing evidence raised. For example, patients with substance use disorder histories were often excluded from randomized studies across several conditions, even though use by patients with these or similar underlying conditions is common (e.g., PTSD and chronic noncancer pain) [208].

\section{Implications for Research, Clinicians, and Policy}

The prevalence of medical cannabis and cannabis use for nonmedical reasons is increasing [209], while perceived risks associated with cannabis use are decreasing, particularly among younger persons [210]. Therefore, it is important to evaluate and disseminate the evidence widely to both clinicians and patients. Interestingly, there is also some evidence suggesting that the legalization of cannabis might not necessarily affect the compliance rate of primary therapies in patients with chronic noncancer pain under opioid therapy [211], so it is unclear whether the changing availability of licit nonmedical cannabis will impact clinical outcomes in patients receiving medical cannabis.

There remains a need for well-designed and conducted RCTs for most of the assessed medical conditions. However, there are several methodological and practical challenges in conducting RCTs specific to investigating efficacy and safety of cannabis and cannabinoids, including placebo effects, practical limitations in conducting blinding for cannabis products, and regulatory barriers. Expense and complicated implementation, meanwhile, render it difficult to design and perform high-quality RCTs even in the absence of cannabis-related regulatory barriers [212, 213]. Studies assessing cannabis efficacy and safety for these conditions, or any condition, must consider the effect that different routes of administration can have on systemic exposure and ultimately on study outcomes. Studies must also clearly and precisely quantify active metabolites and ratio of metabolites (i.e., THC:CBD) with the same rigor as applied to other medication studies.

Questions also remain about medical cannabis safety, especially in terms of rare adverse drug events, long-term effects, the effects on patients with comorbidities (e.g., people with history of substance abuse), and the potential for interactions with prescription medications and other substances, particularly among patients most susceptible to adverse events from drug-drug interactions (e.g., geriatric populations). Future research will require the utilization of a combination of approaches and techniques to overcome the barriers associated with capturing these rare or long-term outcomes, including the use of realworld data and sophisticated pharmacoepidemiologic methods to overcome current limitations in reported studies for ascertaining exposures and outcomes.

The evolving and challenging legal status of cannabis remains a significant obstacle to the expansion of cannabis research in the USA. The schedule I controlled substance designation of whole-plant cannabis restricts research in this area due to regulatory barriers and limited feasibility, along with scarce federal research funding allocated to the investigation of constituent compounds [214]. Furthermore, only a minority of the National Institute of Health's budget is earmarked for therapeutic cannabis research, while more is available for investigations of problematic uses and/or abuse potential, making it challenging to get US funding for investigation of therapeutic potential [215, 216]. The complicated legal status of cannabis in the USA restricts cultivation and production to a single federally permitted institution; thus, a narrow amount of cannabis products can be tested, and these may not mirror constituents and concentrations of products available to consumers on the market $[217,218]$. Thus, policies would need revision to permit handling or production of dispensary-available cannabis products for research purposes and expand funding mechanism to support urgently needed research on clinical outcomes of medical cannabis.
Jugl et al. 


\section{Limitations and Strengths}

Our review has several limitations that should be considered in the interpretation of the findings. First, we restricted our search strategy to studies published between July 2016 and October 2019 and for our rapid review to studies published between 2000 and October 2019. Therefore, we assessed only a narrow period of the most recently available literature. Second, we excluded articles reporting primary research conducted exclusively outside the USA, in order to account for differences in cannabis product availability internationally as well as differences in regulatory barriers and access. We, therefore, have excluded potentially relevant recent literature conducted in countries with robust scientific and clinical research programs evaluating cannabis efficacy and safety. However, studies originating from the USA accounted for almost $2 / 3$ of all publications between 2000 and 2017 [219]. Third, even though we conducted pilot runs and training with reviewers on the use of the data extraction tool, the data extraction step was only conducted by one reviewer with review by a second reviewer in cases of uncertainty. In addition, the screening process for each topic area was only conducted by a second reviewer for those articles categorized as "uncertain"; thus, selection bias might have been introduced during both stages. However, weekly meetings throughout the review process were used to clarify any questions and uncertainties throughout the screening and extraction process. Fourth, systematic reviews and metaanalyses were not excluded if they partially included studies that were not matching our criteria (e.g., a systematic review consisting of studies that were conducted between 2016 and 2019 but also prior to 2016 was still considered as eligible, since it was not feasible to disentangle the evidence synthesis without examining the underlying primary study). Therefore, our findings based on systematic reviews and meta-analyses might not be restricted to our country and time criteria. In order to account for this limitation, we stratified our findings by study design and also restricted our summary of cannabis agents to RCTs and observational studies. Fifth, we did not assess whether medical cannabis was used as adjuvant treatment or primary therapy. Subsequently, different directions of findings might be based on variation in co-medications. However, the regulatory environment in the US mainly restricts the use of medical cannabis products to adjuvants, and the objective of this study was not to assess safety and efficacy of medical cannabis. Last, although a standardized classification scheme was applied to categorize the outcomes, inter-rater variability might have introduced misclassification of the outcomes.

Mapping Review of Medical Cannabis Clinical Outcomes
There are also several strengths of this review to consider, including the broad scope of assessed medical conditions, comprehensive search strategy that extended beyond RCTs, and adherence to the PRISMA statement for gathering and reporting findings. Furthermore, this review highlights recent research efforts by medical condition, and directions of findings, thus creating a comprehensive picture of the scientific landscape of clinical studies about cannabis. Moreover, we also identified several literature gaps that could be addressed in future research, and we assessed the quality of evidence available, which is essential information for policymaking. Additionally, input from an external expert panel ensured a wide range in scope of the literature covered, and this review gives an up-to-date overview about the current state of evidence quality in a readily interpretable map.

\section{Conclusion}

The large body of the literature recently published regarding medical cannabis masks a paucity of evidence related to efficacy and safety as treatment options for several conditions for which it is commonly prescribed. Across 11 conditions, we identified few studies of substantial rigor and quality to contribute to the evidence base. However, there are some conditions for which significant evidence suggests that certain dosage forms and routes of medical cannabis products likely have favorable risk-benefit ratios (i.e., epilepsy and chronic noncancer pain). Gaps in the evidence remain significant for most examined conditions, but the identification of several registered forthcoming RCTs suggests that improved evidence will be available in the coming years.

\section{Acknowledgement}

We thank and acknowledge the panel of scientific and clinical subject matter experts who provided comments on the protocols for topic selection, literature identification search strategies, literature screening, and data extraction procedures. Expert panelists were recruited as part of the Consortium for Medical Marijuana Clinical Outcomes Research activities, but the panelists have not contributed to the interpretation of the review findings.

\section{Conflict of Interest Statement}

The Consortium for Medical Marijuana Clinical Outcomes Research provided funding support for 4 contributors to this study, where S.J. and B.C. received graduate student stipend support in

Med Cannabis Cannabinoids 2021;4:21-42 
2019-2020, and A.G., J.H.C., and A.W. received salary offset for serving as University of Florida faculty leads in 2019-2020. No other authors have conflicts of interest to declare.

\section{Funding Sources}

The consortium (described above) provided material support for 4 authors during the period of study completion (2019-2020). The funder did not have a role in decisions related to the preparation of data or the contents of this manuscript.

\section{Author Contributions}

S.J. prepared protocols for literature search, screening, and data extraction and drafted the manuscript. A.G. designed the study, supervised contributors, and critically revised the manuscript. L.A. performed literature searches and curated the reference library. The following contributors were topic lead reviewers for the following conditions: A.G. in amyotrophic lateral sclerosis, A.O. in human immunodeficiency virus (HIV)/AIDS, B.C. in Crohn's disease and posttraumatic stress disorder, E.J.M. in Parkinson's disease, G.A.H. in epilepsy, S.K. and S.J. in cancer, S.J. in chronic noncancer pain, Y.S. in autism and multiple sclerosis, and Y.Z. in glaucoma. R.S. developed figures. All other contributors were positioned in various roles as screeners, in data extraction, in reviewer resolutions, and in qualitative synthesis. All contributors critically revised and approved the manuscript.

\section{References}

1 State Medical Marijuana Laws: National Conference of State Legislatures; 2020 [updated 2020 Oct 3; cited 2020 Mar 6]. Available from: https: //www.ncsl.org/research/health/statemedical-marijuana-laws.aspx\#1.

2 Heather L, Kimmel P. Marijuana research at the National Institute on drug abuse. Pueblo, Colorado; 2018

3 Boehnke KF, Gangopadhyay S, Clauw DJ, Haffajee RL. Qualifying conditions of medical cannabis license holders in the United States. Health Aff. 2019;38(2):295-302.

4 Azcarate PM, Zhang AJ, Keyhani S, Steigerwald S, Ishida JH, Cohen BE. Medical reasons for marijuana use, forms of use, and patient perception of physician attitudes among the US population. J Gen Intern Med. 2020 Jul; 35(7):1979-86.

5 Compton WM, Han B, Hughes A, Jones CM, Blanco C. Use of marijuana for medical purposes among adults in the United States. JAMA. 2017;317(2):209-11.

6 Hasin DS. US epidemiology of cannabis use and associated problems. Neuropsychopharmacology. 2018;43(1):195-212.

7 Steigerwald S, Wong PO, Cohen BE, Ishida JH, Vali M, Madden E, et al. Smoking, vaping, and use of edibles and other forms of marijuana among U.S. adults. Ann Intern Med. 2018;169(12):890-2.

8 National Academies of Sciences E, and Medicine, Division HaM, Practice $\mathrm{BoPHaPH}$, Agenda CotHEoMAERaR. The health effects of cannabis and cannabinoids. USA: National Academies Press; 2017.

9 Shea BJ, Reeves BC, Wells G, Thuku M, Hamel C, Moran J, et al. AMSTAR 2: a critical appraisal tool for systematic reviews that include randomised or non-randomised studies of healthcare interventions, or both. BMJ. 2017;358:j4008.

10 Grant MJ, Booth A. A typology of reviews: an analysis of 14 review types and associated methodologies. Health Info Libr J. 2009; 26(2):91-108.
11 Ng L, Khan F, Young CA, Galea M. Symptomatic treatments for amyotrophic lateral sclerosis/motor neuron disease. Cochrane Database Syst Rev. 2017;1:Cd011776.

12 Lim K, See YM, Lee J. A systematic review of the effectiveness of medical cannabis for psychiatric, movement and neurodegenerative disorders. Clin Psychopharmacol Neurosci. 2017;15(4):301-12.

13 Harrison D, Mehta P, van Es MA, Stommel E, Drory VE, Nefussy B, et al. ALS reversals: demographics, disease characteristics, treatments, and co-morbidities. Amyotrophic Lateral Scler Frontotemporal Degener. 2018; 19(7-8):495-9.

14 Haug NA, Kieschnick D, Sottile JE, Babson KA, Vandrey R, Bonn-Miller MO. Training and practices of cannabis dispensary staff. Cannabis Cannabinoid Res. 2016;1(1):244-51.

15 Carey CE, Agrawal A, Bucholz KK, Hartz SM, Lynskey MT, Nelson EC, et al. Associations between polygenic risk for psychiatric disorders and substance involvement. Front Genet. 2016 Aug 15;7:149.

16 Barchel D, Stolar O, De-Haan T, Ziv-Baran T, Saban N, Fuchs DO, et al. Oral cannabidiol use in children with autism spectrum disorder to treat related symptoms and co-morbidities. Front Pharmacol. 2018;9:1521.

17 Aran A, Cassuto H, Lubotzky A, Wattad N, Hazan E. Brief report: cannabidiol-rich cannabis in children with autism spectrum disorder and severe behavioral problems-a retrospective feasibility study. J Autism Dev Disord. 2019;49(3):1284-8.

18 Schapir L, Lahav T, Zalsman G, Krivoy A, Sever J, Weizman A, et al. Cigarette smoking, alcohol and cannabis use in patients with pervasive developmental disorders. Subst Use Misuse. 2016;51(11):1415-20

19 Sherva R, Wang Q, Kranzler H, Zhao H, Koesterer R, Herman A, et al. Genome-wide association study of cannabis dependence severity, novel risk variants, and shared genetic risks. JAMA Psychiatry. 2016;73(5):472-80.
20 Raynal P, Goutaudier N, Nidetch V, Chabrol $\mathrm{H}$. Typology of schizotypy in non-clinical young adults: psychopathological and personality disorder traits correlates. Psychiatry Res. 2016;246:182-7.

21 Stringer S, Minică CC, Verweij KJ, Mbarek H, Bernard M, Derringer J, et al. Genome-wide association study of lifetime cannabis use based on a large meta-analytic sample of 32 330 subjects from the International Cannabis Consortium. Transl Psychiatry. 2016;6:e769.

22 Pretzsch CM, Voinescu B, Mendez MA Wichers R, Ajram L, Ivin G, et al. The effect of cannabidiol (CBD) on low-frequency activity and functional connectivity in the brain of adults with and without autism spectrum disorder (ASD). J Psychopharmacol. 2019; 33(9):1141-8.

23 Pretzsch CM, Freyberg J, Voinescu B, Lythgoe D, Horder J, Mendez MA, et al. Effects of cannabidiol on brain excitation and inhibition systems; a randomised placebo-controlled single dose trial during magnetic resonance spectroscopy in adults with and without autism spectrum disorder. Neuropsychopharmacology. 2019;44(8):1398-405.

24 Rabgay K, Waranuch N, Chaiyakunapruk N, Sawangjit R, Ingkaninan K, Dilokthornsakul $P$. The effects of cannabis, cannabinoids, and their administration routes on pain control efficacy and safety: a systematic review and network meta-analysis. J Am Pharm Assoc. 2020 Jan-Feb;60(1):225-34.e6.

25 Aviram J, Samuelly-Leichtag G. Efficacy of cannabis-based medicines for pain management: a systematic review and meta-analysis of randomized controlled trials. Pain Physician. 2017;20(6):E755-96

26 Lobos Urbina D, Peña Durán J. Are cannabinoids effective for treatment of pain in patients with active cancer? Medwave. 2016; 16(Suppl 3):e6539. 
27 Mucke M, Weier M, Carter C, Copeland J, Degenhardt L, Cuhls H, et al. Systematic review and meta-analysis of cannabinoids in palliative medicine. J Cachexia Sarcopenia Muscle. 2018;9(2):220-34.

28 Darkovska-Serafimovska M, Serafimovska T, Arsova-Sarafinovska Z, Stefanoski S, Keskovski Z, Balkanov T. Pharmacotherapeutic considerations for use of cannabinoids to relieve pain in patients with malignant diseases. J Pain Res. 2018;11:837-42.

29 Tateo S. State of the evidence: cannabinoids and cancer pain: a systematic review. J Am Assoc Nurse Pract. 2017;29(2):94-103.

30 Hauser W, Petzke F, Fitzcharles MA. Efficacy, tolerability and safety of cannabis-based medicines for chronic pain management: an overview of systematic reviews. Eur J Pain. 2018; 22(3):455-70.

31 Gouveia DN, Guimarães AG, Santos WBDR, Quintans-Júnior LJ. Natural products as a perspective for cancer pain management: a systematic review. Phytomedicine. 2019;58: 152766.

32 Hou S, Huh B, Kim HK, Kim KH, Abdi S. Treatment of chemotherapy-induced peripheral neuropathy: systematic review and recommendations. Pain Physician. 2018;21(6): 571-92.

33 Schussel V, Kenzo L, Santos A, Bueno J, Yoshimura E, de Oliveira Cruz Latorraca C, et al. Cannabinoids for nausea and vomiting related to chemotherapy: overview of systematic reviews. Phytother Res. 2018;32(4):567-76.

34 Fallon MT, Albert Lux E, McQuade R, Rossetti S, Sanchez R, Sun W, et al. Sativex oromucosal spray as adjunctive therapy in advanced cancer patients with chronic pain unalleviated by optimized opioid therapy: two double-blind, randomized, placebo-controlled phase 3 studies. Br J Pain. 2017;11(3): 119-33.

35 Lichtman AH, Lux EA, McQuade R, Rossetti S, Sanchez R, Sun W, et al. Results of a doubleblind, randomized, placebo-controlled study of nabiximols oromucosal spray as an adjunctive therapy in advanced cancer patients with chronic uncontrolled pain. J Pain Symptom Manage. 2018;55(2):179-88.e1.

36 Anderson SP, Zylla DM, McGriff DM, Arneson TJ. Impact of medical cannabis on patient-reported symptoms for patients with cancer enrolled in Minnesota's Medical Cannabis Program. J Oncol Pract. 2019;15(4): e338-45.

37 Advani SM, Advani PG, Vonville HM, Jafri $\mathrm{SH}$. Pharmacological management of cachexia in adult cancer patients: a systematic review of clinical trials. BMC Cancer. 2018;18(1): 1174.

38 Wang J, Wang Y, Tong M, Pan H, Li D. Medical cannabinoids for cancer cachexia: a systematic review and meta-analysis. Biomed Res Int. 2019;2019:2864384.
39 Muller-Schulte E, Kurlemann G, Harder A. Tobacco, alcohol and illicit drugs during pregnancy and risk of neuroblastoma: systematic review. Arch Dis Child Fetal Neonatal Ed. 2018;103(5):F467-73.

40 Martinasek MP, McGrogan JB, Maysonet A. A systematic review of the respiratory effects of inhalational marijuana. Respir Care. 2016; 61(11):1543-51.

41 Rajanahally S, Raheem O, Rogers M, Brisbane W, Ostrowski K, Lendvay T, et al. The relationship between cannabis and male infertility, sexual health, and neoplasm: a systematic review. Andrology. 2019;7(2):139-47.

42 Nugent SM, Morasco BJ, O’Neil ME, Freeman M, Low A, Kondo K, et al. The effects of cannabis among adults with chronic pain and an overview of general harms: a systematic review. Ann Intern Med. 2017;167(5):319-31.

43 Allen D. Dronabinol therapy: central nervous system adverse events in adults with primary brain tumors. Clin J Oncol Nurs. 2019;23(1): 23-6.

44 Gandhi S, Vasisth G, Kapoor A. Systematic review of the potential role of cannabinoids as antiproliferative agents for urological cancers. Can Urol Assoc J. 2017;11(3-4):E138-2.

45 Brown D, Watson M, Schloss J. Pharmacological evidence of medicinal cannabis in oncology: a systematic review. Support Care Cancer. 2019;27(9):3195-207.

46 Lowe K, Escoffery C, Mertens AC, Berg CJ. Distinct health behavior and psychosocial profiles of young adult survivors of childhood cancers: a mixed methods study. J Cancer Surviv. 2016;10(4):619-32.

47 Elliott DA, Nabavizadeh N, Romer JL, Chen Y, Holland JM. Medical marijuana use in head and neck squamous cell carcinoma patients treated with radiotherapy. Support Care Cancer. 2016;24(8):3517-24.

48 Pergam SA, Woodfield MC, Lee CM, Cheng GS, Baker KK, Marquis SR, et al. Cannabis use among patients at a comprehensive cancer center in a state with legalized medicinal and recreational use. Cancer. 2017;123(22):4488-97.

49 Haug NA, Padula CB, Sottile JE, Vandrey R, Heinz AJ, Bonn-Miller MO. Cannabis use patterns and motives: a comparison of younger, middle-aged, and older medical cannabis dispensary patients. Addict Behav. 2017;72: 14-20.

50 Vin-Raviv N, Akinyemiju T, Meng Q, Sakhuja S, Hayward R. Marijuana use and inpatient outcomes among hospitalized patients: analysis of the nationwide inpatient sample database. Cancer Med. 2017;6(1):320-9.

51 Rauenzahn S, Sima A, Cassel B, Noreika D, Gomez TH, Ryan L, et al. Urine drug screen findings among ambulatory oncology patients in a supportive care clinic. Support Care Cancer. 2017;25(6):1859-64.

52 Braun IM, Meyer FL, Gagne JJ, Nabati L, Yuppa DP, Carmona MA, et al. Experts' perspectives on the role of medical marijuana in oncology: a semistructured interview study. Psychooncology. 2017;26(8):1087-92.
53 Hoffman K, Ponce-Terashima J, McCarty D, Muench J. Toward a patient registry for cannabis use: an exploratory study. Drug Alcohol Depend. 2017;171:e89-90.

54 Mohite PN, Zeriouh M, Sáez DG, Popov AF, Sabashnikov A, Zych B, et al. Influence of history of cannabis smoking in selected donors on the outcomes of lung transplantation. Eur J Cardiothorac Surg. 2017;51(1):142-7.

55 Dai H, Richter KP. A National Survey of marijuana use among US adults with medical conditions, 2016-2017. JAMA Netw Open. 2019; 2(9):e1911936.

56 Philpot LM, Ebbert JO, Hurt RT. A survey of the attitudes, beliefs and knowledge about medical cannabis among primary care providers. BMC Fam Pract. 2019;20(1):17.

57 Donovan KA, Oberoi-Jassal R, Chang YD, Rajasekhara S, Haas MF, Randich AL, et al. Cannabis use in young adult cancer patients. J Adolesc Young Adult Oncol. 2020 Feb;9(1): $30-5$.

58 Adejumo AC, Ajayi TO, Adegbala OM, Adejumo KL, Alliu S, Akinjero AM, et al. Cannabis use is associated with reduced prevalence of progressive stages of alcoholic liver disease. Liver Int. 2018;38(8):1475-86.

59 Singh V, Zarrabi AJ, Curseen KA, Sniecinski R, Welsh JW, McKenzie-Brown AM, et al. Concerns of patients with cancer on accessing cannabis products in a state with restrictive medical marijuana laws: a survey study. J Oncol Pract. 2019;15(10):531.

60 Chang YD, Jung JW, Oberoi-Jassal R, Kim J, Rajasekhara S, Haas M, et al. Edmonton symptom assessment scale and clinical characteristics associated with cannabinoid use in oncology supportive care outpatients. J Natl Compr Canc Netw. 2019;17(9):1059-64.

61 Desai R, Patel U, Goyal H, Rimu AH, Zalavadia D, Bansal P, et al. In-hospital outcomes of inflammatory bowel disease in cannabis users: a nationwide propensity-matched analysis in the United States. Ann Transl Med. 2019;7(12):252.

62 Reblin M, Sahebjam S, Peeri NC, Martinez YC, Thompson Z, Egan KM. Medical cannabis use in glioma patients treated at a comprehensive cancer center in Florida. J Palliat Med. 2019;22(10):1202-7.

63 Saadeh CE, Rustem DR. Medical marijuana use in a community cancer center. J Oncol Practice. 2018;14(9):e566-78.

64 Braun IM, Wright A, Peteet J, Meyer FL, Yuppa DP, Bolcic-Jankovic D, et al. Medical Oncologists' beliefs, practices, and knowledge regarding marijuana used therapeutically: a nationally representative survey study. J Clin Oncol. 2018;36(19):1957-62.

65 Zylla D, Steele G, Eklund J, Mettner J, Arneson T. Oncology clinicians and the minnesota medical cannabis program: a survey on medical cannabis practice patterns, barriers to enrollment, and educational needs. Cannabis Cannabinoid Res. 2018;3(1):195-202.
Mapping Review of Medical Cannabis Clinical Outcomes
Med Cannabis Cannabinoids 2021:4:21-42 DOI: $10.1159 / 000515069$ 
66 Kim A, Kaufmann CN, Ko R, Li Z, Han BH. Patterns of medical cannabis use among cancer patients from a medical cannabis dispensary in New York State. J Palliat Med. 2019; 22(10):1196-201.

67 Zarrabi AJ, Welsh JW, Sniecinski R, Curseen K, Gillespie T, Baer W, et al. Perception of benefits and harms of medical cannabis among seriously ill patients in an outpatient palliative care practice. J Palliat Med. 2020 Apr;23(4):558-62.

68 Bruce D, Brady JP, Foster E, Shattell M. Preferences for medical marijuana over prescription medications among persons living with chronic conditions: alternative, complementary, and tapering uses. J Altern Complement Med. 2018;24(2):146-53.

69 Ananth P, Ma C, Al-Sayegh H, Kroon L, Klein $\mathrm{V}$, Wharton C, et al. Provider perspectives on use of medical marijuana in children with cancer. Pediatrics. 2018;141(1):e20170559.

70 Adejumo AC, Adegbala OM, Adejumo KL, Bukong TN. Reduced incidence and better liver disease outcomes among chronic HCV infected patients who consume cannabis. Can J Gastroenterol Hepatol. 2018 Sep 23;2018: 9430953.

71 Donovan KA, Chang YD, Oberoi-Jassal R, Rajasekhara S, Smith J, Haas M, et al. Relationship of cannabis use to patient-reported symptoms in cancer patients seeking supportive/palliative care. J Palliat Med. 2019;22(10):1191-5.

72 Tringale KR, Huynh-Le MP, Salans M, Marshall DC, Shi Y, Hattangadi-Gluth JA. The role of cancer in marijuana and prescription opioid use in the United States: a populationbased analysis from 2005 to 2014. Cancer. 2019;125(13):2242-51.

73 Wall MM, Liu J, Hasin DS, Blanco C, Olfson M. Use of marijuana exclusively for medical purposes. Drug Alcohol Depend. 2019;195: 13-5.

74 Gouveia DN, Guimarães AG, Santos WBDR, Quintans-Júnior LJ. Natural products as a perspective for cancer pain management: a systematic review. Phytomedicine. 2019;58: 152766.

75 van den Beuken-van Everdingen $\mathrm{MH}$, de Graeff A, Jongen JL, Dijkstra D, Mostovaya I, Vissers KC. Pharmacological treatment of pain in cancer patients: the role of adjuvant analgesics, a systematic review. Pain Pract. 2017;17(3):409-19.

76 Nct. A study of the efficacy of cannabidiol in patients with multiple myeloma, glioblastoma multiforme, and GI malignancies. 2018 Available from: https://clinicaltrialsgov/ show/NCT03607643.

77 Nct. Cannabinoids for taxane induced peripheral neuropathy. 2018. Available from: https://clinicaltrialsgov/show/NCT03782402.

78 Kosiba JD, Mitzel LD, Zale EL, Zvolensky MJ Ditre JW. A preliminary study of associations between discomfort intolerance, pain severity/interference, and frequency of cannabis use among individuals with chronic pain. Addict Res Theory. 2020;28(1):76-81.
79 Vigil JM, Stith SS, Adams IM, Reeve AP. As sociations between medical cannabis and prescription opioid use in chronic pain patients: a preliminary cohort study. PLoS One. 2017; 12(11): 0187795.

80 Bilevicius E, Sommer JL, Asmundson GJG, El-Gabalawy R. Associations of PTSD, chronic pain, and their comorbidity on cannabis use disorder: results from an American nationally representative study. Depress Anxiety. 2019 Nov;36(11):1036-46.

81 Sohler NL, Starrels JL, Khalid L, Bachhuber MA, Arnsten JH, Nahvi S, et al. Cannabis use is associated with lower odds of prescription opioid analgesic use among HIV-infected individuals with chronic pain. Subst Use Misuse. 2018 Aug;53(10):1602-7.

82 Boehnke KF, Scott JR, Litinas E, Sisley S, Clauw DJ, Goesling J, et al. Cannabis use preferences and decision-making among a crosssectional cohort of medical cannabis patients with chronic pain. J Pain. 2019 Nov;20(11): $1362-2$.

83 Reynolds IR, Fixen DR, Parnes BL, Lum HD, Shanbhag P, Church S, et al. Characteristics and patterns of marijuana use in communitydwelling older adults. J Am Geriatr Soc. 2018; 66(11):2167-71.

84 Piper BJ, Beals ML, Abess AT, Nichols SD, Martin MW, Cobb CM, et al. Chronic pain patients' perspectives of medical cannabis. Pain. 2017;158(7):1373-9.

85 Freisthler B, Cooke A. Do characteristics of marijuana use correspond to overall health levels for medical marijuana patients? J Subst Use. 2018;23(3):307-11.

86 Delling FN, Vittinghoff E, Dewland TA, Pletcher MJ, Olgin JE, Nah G, et al. Does cannabis legalisation change healthcare utilisation? A population-based study using the healthcare cost and utilisation project in Colorado, USA. BMJ Open. 2019;9(5):e027432.

87 Barlowe TS, Koliani-Pace JL, Smith KD, Gordon SR, Gardner TB. Effects of medical cannabis on use of opioids and hospital visits by patients with painful chronic pancreatitis. Clin Gastroenterol Hepatol. 2019 Nov; 17(12): 2608-9.e1.

88 Gill HK, Young SD. Exploring cannabis use reasons and experiences among mobile cannabis delivery patients. J Subst Use. 2019; 24(1):15-20.

89 Davis AK, Bonar EE, Ilgen MA, Walton MA, Perron BE, Chermack ST. Factors associated with having a medical marijuana card among Veterans with recent substance use in VA outpatient treatment. Addict Behav. 2016;63: 132-6.

90 Orr MF, Rogers AH, Shepherd JM, Buckner JD, Ditre JW, Bakhshaie J, et al. Is there a relationship between cannabis use problems, emotion dysregulation, and mental health problems among adults with chronic pain? Psychol Health Med. 2020 Jul;25:742-55.
91 Sinha CB, Bakshi N, Ross D, Krishnamurti L. Management of chronic pain in adults living with sickle cell disease in the era of the opioid epidemic: a qualitative study. JAMA Netw Open. 2019;2(5):e194410.

92 Mercurio A, Aston ER, Claborn KR, Waye K, Rosen RK. Marijuana as a substitute for prescription medications: a qualitative study. Subst Use Misuse. 2019;54(11):1894902.

93 Cobb S, Bazargan M, Smith J, Del Pino HE, Dorrah K, Assari S. Marijuana use among African American older adults in economically challenged areas of South Los Angeles. Brain Sci. 2019;9(7):166.

94 Shah A, Craner J, Cunningham JL. Medical cannabis use among patients with chronic pain in an interdisciplinary pain rehabilitation program: characterization and treatment outcomes. J Subst Abuse Treat. 2017; 77:95-100.

95 Carlini BH, Garrett SB, Carter GT. Medicinal cannabis: a survey among health care providers in Washington State. Am J Hosp Palliat Care. 2017;34(1):85-91.

96 Rogers AH, Bakhshaie J, Buckner JD, Orr MF, Paulus DJ, Ditre JW, et al. Opioid and cannabis co-use among adults with chronic pain: relations to substance misuse, mental health, and pain experience. J Addict Med. 2019 Jul/Aug; 13(4):287-94.

97 Fales JL, Ladd BO, Magnan RE. Pain relief as a motivation for cannabis use among young adult users with and without chronic pain. J Pain. 2019;20(8):908-16.

98 Cohen NL, Heinz AJ, Ilgen M, Bonn-Miller MO. Pain, Cannabis species, and cannabis use disorders. J Stud Alcohol Drugs. 2016; 77(3):515-20.

99 Kosiba JD, Maisto SA, Ditre JW. Patient-reported use of medical cannabis for pain, anxiety, and depression symptoms: systematic review and meta-analysis. Soc Sci Med. 2019;233:181-92.

100 Cooke AC, Knight KR, Miaskowski C. Patients' and clinicians' perspectives of co-use of cannabis and opioids for chronic noncancer pain management in primary care. Int J Drug Policy. 2019;63:23-8.

101 Nugent SM, Yarborough BJ, Smith NX, Dobscha SK, Deyo RA, Green CA, et al. Patterns and correlates of medical cannabis use for pain among patients prescribed longterm opioid therapy. Gen Hosp Psychiatry. 2018;50:104-10.

102 Khelemsky Y, Goldberg AT, Hurd YL, Winkel G, Ninh A, Qian L, et al. Perioperative patient beliefs regarding potential effectiveness of marijuana (cannabinoids) for treatment of pain: a prospective population survey. Reg Anesth Pain Med. 2017;42(5):6529.

103 Boehnke KF, Scott JR, Litinas E, Sisley S, Williams DA, Clauw DJ. Pills to pot: observational analyses of cannabis substitution among medical cannabis users with chronic pain. J Pain. 2019;20(7):830-41. 
104 Piper BJ, Dekeuster RM, Beals ML, Cobb CM, Burchman CA, Perkinson L, et al. Substitution of medical cannabis for pharmaceutical agents for pain, anxiety, and sleep. J Psychopharmacol. 2017;31(5):569-75.

105 DiBenedetto DJ, Weed VF, Wawrzyniak KM, Finkelman M, Paolini J, Schatman ME, et al. The association between cannabis use and aberrant behaviors during chronic opioid therapy for chronic pain. Pain Med. 2018;19(10):1997-2008.

106 Bachhuber M, Arnsten JH, Wurm G. Use of cannabis to relieve pain and promote sleep by customers at an adult use dispensary. J Psychoactive Drugs. 2019 Nov-Dec;51(5):400-4.

107 Perron BE, Holt KR, Yeagley E, Ilgen M. Mental health functioning and severity of cannabis withdrawal among medical cannabis users with chronic pain. Drug Alcohol Depend. 2019;194:401-9.

108 Nielsen S, Sabioni P, Trigo JM, Ware MA, Betz-Stablein BD, Murnion B, et al. Opioidsparing effect of cannabinoids: a systematic review and meta-analysis. Neuropsychopharmacology. 2017;42(9):1752-65.

109 Orhurhu V, Olusunmade M, Urits I, Viswanath O, Peck J, Orhurhu MS, et al. Trends of opioid use disorder among hospitalized patients with chronic pain. Pain Pract. 2019; 19(6):656-63.

110 Hawley LA, Ketchum JM, Morey C, Collins $\mathrm{K}$, Charlifue S. Cannabis use in individuals with spinal cord injury or moderate to severe traumatic brain injury in Colorado. Arch Phys Med Rehabil. 2018;99(8):1584-90.

111 Stockings E, Campbell G, Hall WD, Nielsen S, Zagic D, Rahman R, et al. Cannabis and cannabinoids for the treatment of people with chronic noncancer pain conditions: a systematic review and meta-analysis of controlled and observational studies. Pain. 2018; 159(10):1932-54.

112 Mucke M, Phillips T, Radbruch L, Petzke F, Hauser W. Cannabis-based medicines for chronic neuropathic pain in adults. Cochrane Database Syst Rev. 2018;3:Cd012182.

113 Yanes JA, McKinnell ZE, Reid MA, Busler JN, Michel JS, Pangelinan MM, et al. Effects of cannabinoid administration for pain: a meta-analysis and meta-regression. Exp Clin Psychopharmacol. 2019;27(4):370-82.

114 Meng H, Johnston B, Englesakis M, Moulin DE, Bhatia A. Selective cannabinoids for chronic neuropathic pain: a systematic review and meta-analysis. Anesth Analg. 2017; 125(5):1638-52.

115 Goldenberg M, Reid MW, IsHak WW, Danovitch I. The impact of cannabis and cannabinoids for medical conditions on healthrelated quality of life: a systematic review and meta-analysis. Drug Alcohol Depend. 2017;174:80-90.

116 Millar SA, Stone NL, Bellman ZD, Yates AS, England TJ, O'Sullivan SE. A systematic review of cannabidiol dosing in clinical populations. Br J Clin Pharmacol. 2019;85(9): 1888-900.
117 Walitt B, Klose P, Fitzcharles MA, Phillips T, Häuser W. Cannabinoids for fibromyalgia. Cochrane Database Syst Rev. 2016; 7: CD011694.

118 Merlin JS, Long D, Becker WC, Cachay ER, Christopolous KA, Claborn KR, et al. Marijuana use is not associated with changes in opioid prescriptions or pain severity among people living with hiv and chronic pain. J Acquir Immune Defic Syndr. 2019;81(2): 231-7.

119 Fitzcharles MA, Baerwald C, Ablin J, Hauser W. Efficacy, tolerability and safety of cannabinoids in chronic pain associated with rheumatic diseases (fibromyalgia syndrome, back pain, osteoarthritis, rheumatoid arthritis) a systematic review of randomized controlled trials. Schmerz. 2016; 30(1):47-61.

120 Merlin JS, Bulls HW, Vucovich LA, Edelman EJ, Starrels JL. Pharmacologic and nonpharmacologic treatments for chronic pain in individuals with HIV: a systematic review. AIDS Care. 2016;28(12):1506-15.

$121 \mathrm{Mu} \mathrm{A}$, Weinberg E, Moulin DE, Clarke H Pharmacologic management of chronic neuropathic pain: review of the Canadian Pain Society consensus statement. Can Fam Physician. 2017;63(11):844-52.

122 Kansagara D, O’Neil M, Nugent S, Freeman M, Low A, Kondo K, et al. VA Evidencebased synthesis program reports. Benefits and harms of cannabis in chronic pain or post-traumatic stress disorder: a systematic review. Washington, DC: Department of Veterans Affairs (US); 2017.

123 Nct. Mechanisms of CBD for Chronic Pain. 2019. Available from: https://clinicaltrialsgov/show/NCT04044729.

124 Nct. Sublingual Cannabidiol for Chronic Pain. 2019. Available from: https://clinicaltrialsgov/show/NCT03984565.

125 Nct. Treatment of Chronic Pain With Cannabidiol (CBD) and Delta-9-tetrahydrocannabinol (THC). 2017. Available from: https: //clinicaltrialsgov/show/NCT03215940.

126 Hoffenberg EJ, McWilliams S, MikulichGilbertson S, Murphy B, Hoffenberg A, Hopfer CJ. Cannabis oil use by adolescents and young adults with inflammatory bowel disease. J Pediatr Gastroenterol Nutr. 2019; 68(3):348-52.

127 Kerlin AM, Long M, Kappelman M, Martin C, Sandler RS. Profiles of patients who use marijuana for inflammatory bowel disease. Dig Dis Sci. 2018;63(6):1600-4.

128 Sexton M, Cuttler C, Finnell JS, Mischley LK. A cross-sectional survey of medical cannabis users: patterns of use and perceived efficacy. Cannabis Cannabinoid Res. 2016; $1(1): 131-8$

129 Hoffenberg EJ, McWilliams SK, MikulichGilbertson SK, Murphy BV, Lagueux M, Robbins K, et al. Marijuana use by adolescents and young adults with inflammatory bowel disease. J Pediatr. 2018;199:99105.
130 Mbachi C, Attar B, Wang Y, Paintsil I, Mba B, Fugar S, et al. Association between cannabis use and complications related to Crohn's disease: a retrospective cohort study. Dig Dis Sci. 2019;64(10):2939-44.

131 Kafil TS, Nguyen TM, MacDonald JK, Chande N. Cannabis for the treatment of Crohn's disease. Cochrane Database Syst Rev. 2018;11(11):CD012853.

132 Phatak UP, Rojas-Velasquez D, Porto A, Pashankar DS. Prevalence and patterns of marijuana use in young adults with inflammatory bowel disease. J Pediatr Gastroenterol Nutr. 2017;64(2):261-4.

133 Nct. Cannabidiol Usage as an Adjunct Therapy for Crohn's Disease. 2018. Available from: https://clinicaltrialsgov/show/ NCT03467620.

134 Hess EJ, Moody KA, Geffrey AL, Pollack SF, Skirvin LA, Bruno PL, et al. Cannabidiol as a new treatment for drug-resistant epilepsy in tuberous sclerosis complex. Epilepsia. 2016;57(10):1617-24.

135 Szaflarski JP, Bebin EM, Cutter G, DeWolfe J, Dure LS, Gaston TE, et al. Cannabidiol improves frequency and severity of seizures and reduces adverse events in an open-label add-on prospective study. Epilepsy Behav. 2018;87:131-6.

136 Thiele EA, Marsh ED, French JA, Mazurkiewicz-Beldzinska M, Benbadis SR, Joshi C, et al. Cannabidiol in patients with seizures associated with Lennox-Gastaut syndrome (GWPCARE4): a randomised, doubleblind, placebo-controlled phase 3 trial. Lancet. 2018;391(10125):1085-96.

137 Elliott J, DeJean D, Clifford T, Coyle D, Potter BK, Skidmore B, et al. Cannabis-based products for pediatric epilepsy: a systematic review. Epilepsia. 2019;60(1):6-19.

138 Lattanzi S, Brigo F, Trinka E, Zaccara G, Cagnetti C, Del Giovane C, et al. Efficacy and safety of cannabidiol in epilepsy: a systematic review and meta-analysis. Drugs. 2018; 78(17):1791-804.

139 Szaflarski JP, Hernando K, Bebin EM, Gaston TE, Grayson LE, Ampah SB, et al. Higher cannabidiol plasma levels are associated with better seizure response following treatment with a pharmaceutical grade cannabidiol. Epilepsy Behav. 2019;95:131-6.

140 Devinsky O, Nabbout R, Miller I, Laux L, Zolnowska M, Wright S, et al. Long-term cannabidiol treatment in patients with Dravet syndrome: an open-label extension trial. Epilepsia. 2019;60(2):294-302.

141 Szaflarski JP, Bebin EM, Comi AM, Patel $\mathrm{AD}$, Joshi C, Checketts D, et al. Long-term safety and treatment effects of cannabidiol in children and adults with treatment-resistant epilepsies: expanded access program results. Epilepsia. 2018;59(8):1540-8. 
142 Sands TT, Rahdari S, Oldham MS, Caminha Nunes E, Tilton N, Cilio MR. Long-term safety, tolerability, and efficacy of cannabidiol in children with refractory epilepsy: results from an expanded access program in the US. CNS Drugs. 2019;33(1):47-60.

143 Wong SS, Wilens TE. Medical cannabinoids in children and adolescents: a systematic review. Pediatrics. 2017;140(5):e20171818.

144 Gaston TE, Szaflarski M, Hansen B, Bebin EM, Szaflarski JP. Quality of life in adults enrolled in an open-label study of cannabidiol (CBD) for treatment-resistant epilepsy. Epilepsy Behav. 2019;95:10-7.

145 Devinsky O, Cross JH, Laux L, Marsh E, Miller I, Nabbout R, et al. Trial of cannabidiol for drug-resistant seizures in the Dravet syndrome. N Engl J Med. 2017;376(21): 2011-20.

146 Knupp KG, Rice JD, Helmkamp LJ, Galinkin J, Sempio C, Jost K, et al. Prospective evaluation of oral cannabis extracts in children with epilepsy. Seizure. 2019;72:23-7.

147 Martin RC, Gaston TE, Thompson M, Ampah SB, Cutter G, Bebin EM, et al. Cognitive functioning following long-term cannabidiol use in adults with treatment-resistant epilepsy. Epilepsy Behav. 2019;97:105-10.

148 Pamplona FA, da Silva LR, Coan AC. Potential clinical benefits of CBD-rich cannabis extracts over purified CBD in treatment-resistant epilepsy: observational data metaanalysis (vol 9, 759, 2018). Front Neurol. 2019;9:759.

149 Kaplan EH, Offermann EA, Sievers JW, Comi AM. Cannabidiol treatment for refractory seizures in Sturge-Weber syndrome. Pediatr Neurol. 2017;71:18-e2.

150 Porcari GS, Fu C, Doll ED, Carter EG, Carson RP. Efficacy of artisanal preparations of cannabidiol for the treatment of epilepsy: practical experiences in a tertiary medical center. Epilepsy Behav. 2018;80:240-6.

151 Thiele E, Marsh E, Mazurkiewicz-Beldzinska M, Halford JJ, Gunning B, Devinsky O, et al. Cannabidiol in patients with LennoxGastaut syndrome: interim analysis of an open-label extension study. Epilepsia. 2019; 60(3):419-28.

152 Treat L, Chapman KE, Colborn KL, Knupp KG. Duration of use of oral cannabis extract in a cohort of pediatric epilepsy patients. Epilepsia. 2017;58(1):123-7.

153 Devinsky O, Patel AD, Thiele EA, Wong $\mathrm{MH}$, Appleton R, Harden CL, et al. Randomized, dose-ranging safety trial of cannabidiol in Dravet syndrome. Neurology. 2018; 90(14):e1204-11.

154 Wheless JW, Dlugos D, Miller I, Oh DA, Parikh N, Phillips S, et al. Pharmacokinetics and tolerability of multiple doses of pharmaceutical-grade synthetic cannabidiol in pediatric patients with treatment-resistant epilepsy. CNS Drugs. 2019;33(6):593-604.
155 Gaston TE, Bebin EM, Cutter GR, Liu Y, Szaflarski JP, Program UC. Interactions between cannabidiol and commonly used antiepileptic drugs. Epilepsia. 2017;58(9): 1586-92.

156 Gaston TE, Bebin EM, Cutter GR, Ampah SB, Liu Y, Grayson LP, et al. Drug-drug interactions with cannabidiol (CBD) appear to have no effect on treatment response in an open-label Expanded Access Program. Epilepsy Behav. 2019;98(Pt A):201-6.

157 Gaston TE, Bebin EM, Cutter GR, Liu Y, Szaflarski JP. Interactions between cannabidiol and commonly used antiepileptic drugs. Epilepsia. 2017;58(9):1586-92.

158 Kerr A, Walston V, Wong VSS, Kellogg M, Ernst L. Marijuana use among patients with epilepsy at a tertiary care center. Epilepsy Behav. 2019;97:144-8.

159 Gamarel KE, Nichols S, Kahler CW, Westfall AO, Lally MA, Wilson CM. A cross-sectional study examining associations between substance use frequency, problematic use and STIs among youth living with HIV. Sex Transm Infect. 2018;94(4):304-8.

160 Morgan E, Khanna AS, Skaathun B, Michaels S, Young L, Duvoisin R, et al. Marijuana use among young black men who have sex with men and the HIV care continuum: findings from the uConnect cohort. Subst Use Misuse. 2016;51(13):1751-9.

161 Vidot DC, Lerner B, Gonzalez R. Cannabis use, medication management and adherence among persons living with HIV. AIDS Behav. 2017;21(7):2005-13.

162 Mannes ZL, Burrell LE 2nd, Ferguson EG, Zhou Z, Lu H, Somboonwit C, et al. The association of therapeutic versus recreational marijuana use and antiretroviral adherence among adults living with HIV in Florida. Patient Prefer Adherence. 2018;12:1363-72.

163 Thompson AB, Gillespie SE, Hood J, Thomas-Seaton L, Hussen SA, Camacho-Gonzalez AF. Regular marijuana use is associated with poor viral suppression in HIV-infected adolescents and young adults. AIDS Behav. 2018;22(4):1363-72.

164 Jolley SE, Welsh DA. Substance use is independently associated with pneumonia severity in persons living with the human immunodeficiency virus (HIV). Subst Abus. 2019; 40(2):256-61.

165 Hartzler B, Carlini BH, Newville H, Crane HM, Eron JJ, Geng EH, et al. Identifying HIV care enrollees at-risk for cannabis use disorder. AIDS Care. 2017;29(7):846-50.

166 Noorhasan M, Drozd DR, Grunfeld C, Merrill JO, Burkholder GA, Mugavero MJ, et al. Associations between at-risk alcohol use, substance use, and smoking with lipohypertrophy and lipoatrophy among patients living with HIV. AIDS Res Hum Retroviruses. 2017;33(6):534-45.
167 Okafor CN, Cook RL, Chen XG, Surkan PJ, Becker JT, Shoptaw S, et al. Trajectories of marijuana use among HIV-seropositive and HIV-seronegative MSM in the Multicenter AIDS Cohort Study (MACS). AIDS Behav. 2017 Apr;21(4):1091-104.

168 Kipp AM, Rebeiro PF, Shepherd BE, Brinkley-Rubinstein L, Turner M, Bebawy S, et al. Daily Marijuana use is associated with missed clinic appointments among HIV-infected persons engaged in HIV care. AIDS Behav. 2017;21(7):1996-2004

169 Lee JY, Brook JS, Pahl K. Human immunodeficiency virus (HIV) risk behaviors by African American and Puerto Rican women in the 4(th) decade of life: substance use and personal attributes. J Prev Med. 2018;3(3): 22.

170 Bruce D, Bouris AM, Bowers S, Blocker O, Lee SY, Glidden MF, et al. Medical, therapeutic, and recreational use of cannabis among young men who have sex with men living with HIV. Addict Res Theory. 2020; 28(3):250-9.

171 Gross IM, Hosek S, Richards MH, Fernandez MI. Predictors and profiles of antiretroviral therapy adherence among African American adolescents and young adult males living with HIV. AIDS Patient Care STDS. 2016;30(7):324-38.

172 Zhang Y, Wilson TE, Adedimeji A, Merenstein D, Milam J, Cohen J, et al. The impact of substance use on adherence to antiretroviral therapy among HIV-infected women in the United States. AIDS Behav. 2018; 22(3):896-908.

173 Sinha S, McCaul ME, Hutton HE, Monroe AK, Alvanzo A, Lesko C, et al. Marijuana use and HIV treatment outcomes among PWH receiving care at an urban HIV clinic. J Subst Abuse Treat. 2017;82:102-6.

174 Montgomery L, Bagot K, Brown JL, Haeny $\mathrm{AM}$. The association between marijuana use and HIV continuum of care outcomes: a systematic review. Curr HIV/AIDS Rep. 2019; 16(1):17-28.

175 Thames AD, Mahmood Z, Burggren AC, Karimian A, Kuhn TP. Combined effects of HIV and marijuana use on neurocognitive functioning and immune status. AIDS Care. 2016;28(5):628-32.

176 Lorenz DR, Dutta A, Mukerji SS, Holman A, Uno H, Gabuzda D. Marijuana use impacts midlife cardiovascular events in HIV-infected men. Clin Infect Dis. 2017;65(4):626-35.

177 Adams JW, Bryant KJ, Edelman EJ, Fiellin DA, Gaither JR, Gordon AJ, et al. Association of cannabis, stimulant, and alcohol use with mortality prognosis among HIV-infected men. AIDS Behav. 2018;22(4):134151.

178 Gamarel KE, Brown L, Kahler CW, Fernan$\operatorname{dez}$ MI, Bruce D, Nichols S. Prevalence and correlates of substance use among youth living with HIV in clinical settings. Drug Alcohol Depend. 2016;169:11-8. 
179 da Rovare VP, Magalhães GPA, Jardini GDA, Beraldo ML, Gameiro MO, Agarwal A, et al. Cannabinoids for spasticity due to multiple sclerosis or paraplegia: a systematic review and meta-analysis of randomized clinical trials. Complement Ther Med. 2017; 34:170-85.

180 Nielsen S, Germanos R, Weier M, Pollard J, Degenhardt L, Hall W, et al. The Use of Cannabis and cannabinoids in treating symptoms of multiple sclerosis: a systematic review of reviews. Curr Neurol Neurosci Rep. 2018;18(2):8.

181 Akgun K, Essner U, Seydel C, Ziemssen T. Daily practice managing resistant multiple sclerosis spasticity with delta-9-tetrahydrocannabinol: cannabidiol oromucosal spray: a systematic review of observational studies. J Cent Nerv Syst Dis. 2019;11.

182 Fu X, Wang Y, Wang C, Wu H, Li J, Li M, et al. A mixed treatment comparison on efficacy and safety of treatments for spasticity caused by multiple sclerosis: a systematic review and network meta-analysis. Clin Rehabil. 2018;32(6):713-21.

183 Torres-Moreno MC, Papaseit E, Torrens M, Farré M. Assessment of efficacy and tolerability of medicinal cannabinoids in patients with multiple sclerosis: a systematic review and meta-analysis. JAMA Netw Open. 2018; 1(6):e183485.

184 Abo Youssef N, Schneider MP, Mordasini L, Ineichen BV, Bachmann LM, Chartier-Kastler E, et al. Cannabinoids for treating neurogenic lower urinary tract dysfunction in patients with multiple sclerosis: a systematic review and meta-analysis. BJU Int. 2017; 119(4):515-21.

185 Behm K, Morgan P. The effect of symptomcontrolling medication on gait outcomes in people with multiple sclerosis: a systematic review. Disabil Rehabil. 2018;40(15):1733-44.

186 Nct. A Study of Tolerability and Efficacy of Cannabidiol on Tremor in Parkinson's Disease. 2016. Available from: https://clinicaltrialsgov/show/NCT02818777.

187 Nct. A Study of Tolerability and Efficacy of Cannabidiol on Motor Symptoms in Parkinson's Disease. 2018. Available from: https:// clinicaltrialsgov/show/NCT03582137.

188 Bega D, Simuni T, Okun MS, Chen X, Schmidt P. Medicinal cannabis for Parkinson's disease: practices, beliefs, and attitudes among providers at National Parkinson Foundation Centers of Excellence. Mov Disord Clin Pract. 2017 Jan-Feb;4(1):90-5.

189 Kindred JH, Li K, Ketelhut NB, Proessl F, Fling BW, Honce JM, et al. Cannabis use in people with Parkinson's disease and multiple sclerosis: a web-based investigation. Complement Ther Med. 2017;33:99-104.

190 Loflin M, Earleywine M, Bonn-Miller M. Medicinal versus recreational cannabis use: patterns of cannabis use, alcohol use, and cued-arousal among veterans who screen positive for PTSD. Addict Behav. 2017;68: $18-23$.
191 Rosenberg J, Loflin MJE, Hurd YL, BonnMiller MO. Prescribing health care providers' attitudes, experiences, and practices surrounding cannabis use in patients with anxiety disorders and post-traumatic stress disorder. Cannabis Cannabinoid Res. 2019; 4(2):124-30.

192 Mammen G, Rueda S, Roerecke M, Bonato S, Lev-Ran S, Rehm J. Association of Cannabis with long-term clinical symptoms in anxiety and mood disorders: a systematic review of prospective studies. J Clin Psychiatry. 2018;79(4).

193 Hoch E, Niemann D, von Keller R, Schneider M, Friemel CM, Preuss UW, et al. How effective and safe is medical cannabis as a treatment of mental disorders? A systematic review. Eur Arch Psychiatry Clin Neurosci. 2019;269(1):87-105.

194 Hindocha C, Cousijn J, Rall M, Bloomfield MAP. The effectiveness of cannabinoids in the treatment of posttraumatic stress disorder (PTSD): a systematic review. J Dual Diagn. 2020 Jan-Mar; 16(1):120-39.

195 Bonaccorso S, Ricciardi A, Zangani C, Chiappini S, Schifano F. Cannabidiol (CBD) use in psychiatric disorders: a systematic review. Neurotoxicology. 2019;74:282-98.

196 Walsh Z, Gonzalez R, Crosby K, Thiessen M, Carroll C, Bonn-Miller MO. Medical cannabis and mental health: a guided systematic review. Clin Psychol Rev. 2017;51:15-29.

197 Orsolini L, Chiappini S, Volpe U, Berardis D, Latini R, Papanti GD, et al. Use of medicinal cannabis and synthetic cannabinoids in post-traumatic stress disorder (PTSD): a systematic review. Medicina. 2019;55(9): 525.

198 Wilkinson ST, Radhakrishnan R, D'Souza DC. A systematic review of the evidence for medical marijuana in psychiatric indications. J Clin Psychiatry. 2016;77(8):1050-64.

199 O’Neil ME, Nugent SM, Morasco BJ, Freeman M, Low A, Kondo K, et al. Benefits and harms of plant-based cannabis for posttraumatic stress disorder: a systematic review. Ann Intern Med. 2017;167(5):332-40.

200 Nct. Effects of Delta-9 Tetrahydrocannabinol (THC) on Retention of Memory for Fear Extinction Learning in PTSD: R61 Study. 2016. Available from: https://clinicaltrialsgov/show/NCT03008005.

201 Nct. Study of Four Different Potencies of Smoked Marijuana in 76 Veterans With PTSD. 2016. Available from: https://clinicaltrialsgov/show/NCT02759185.

202 Nct. Nabilone in Cannabis Users With PTSD. 2017. Available from: https://clinicaltrialsgov/show/NCT03251326.

203 Nct. Cannabidiol and Prolonged Exposure. 2018. Available from: https://clinicaltrialsgov/show/NCT03518801.

204 Nct. Effects of Delta9-tetrahydrocannabinol (THC) on Retention of Memory for Fear Extinction Learning in PTSD: R33 Study. 2019. Available from: https://clinicaltrialsgov/ show/NCT04080427.
205 Johnson T, Fendrich M. Modeling sources of self-report bias in a survey of drug use epidemiology. Ann Epidemiol. 2005;15(5): 381-9.

206 Morral AR, McCaffrey D, Iguchi MY. Hardcore drug users claim to be occasional users: drug use frequency underreporting. Drug Alcohol Depend. 2000;57(3):193-202.

207 Vandrey R, Raber JC, Raber ME, Douglass B, Miller C, Bonn-Miller MO. Cannabinoid dose and label accuracy in edible medical cannabis products. JAMA. 2015;313(24) 2491-3.

208 Campbell G, Stockings E, Nielsen S. Understanding the evidence for medical cannabis and cannabis-based medicines for the treatment of chronic non-cancer pain. Eur Arch Psychiatry Clin Neurosci. 2019;269(1):13544.

209 Compton WM, Han B, Jones CM, Blanco C, Hughes A. Marijuana use and use disorders in adults in the USA, 2002-14: analysis of annual cross-sectional surveys. Lancet Psychiatry. 2016;3(10):954-64.

210 Sarvet AL, Wall MM, Keyes KM, Cerdá M, Schulenberg JE, O'Malley PM, et al. Recent rapid decrease in adolescents' perception that marijuana is harmful, but no concurrent increase in use. Drug Alcohol Depend. 2018;186:68-74.

211 Lo S-Y, Winston-McPherson GN, Starosta AJ, Sullivan MD, Baird GS, Hoofnagle AN, et al . Cannabis legalization does not influence patient compliance with opioid therapy. Am J Med. 2019;132(3):347-53.

212 Casarett D. The Achilles heel of medical cannabis research-inadequate blinding of placebo-controlled trials. JAMA Intern Med. 2018;178(1):9-10.

213 Russo EB. Current therapeutic cannabis controversies and clinical trial design issues. Front Pharmacol. 2016;7:309.

214 Nutt DJ, King LA, Nichols DE. Effects of schedule I drug laws on neuroscience research and treatment innovation. Nat Rev Neurosci. 2013;14(8):577-85.

215 NIDA. NIH: Research on Marijuana and Cannabinoids: National Institute on Drug Abuse. 2020 [cited 2020 May 6]. Available from: https://www.drugabuse.gov/drugsabuse/marijuana/nih-research-marijuanacannabinoids.

216 NIH. Estimates of Funding for Various Research, Condition, and Disease Categories (RCDC). 2020 [cited 2020 May 6]. Available from: https://report.nih.gov/categorical_ spending.aspx.

217 NIDA. Drug supply program catalog. 29th ed. 2019 [updated October 2019; cited 2020 May 6]. Available from: https://d14rmgtrwzf5a.cloudfront.net/sites/default/files/ ndsp_catalog_29.pdf. 
218 NIDA. Information on Marijuana Farm Contract: NIDA. 2020 [updated 2020 Feb; cited 2020 May 6]. Available from: https:// www.drugabuse.gov/drugs-abuse/marijuana/nidas-role-in-providing-marijuana-research/information-marijuana-farm-contract.

219 Treister-Goltzman Y, Freud T, Press Y, Peleg R. Trends in publications on medical cannabis from the year 2000. Popul Health Manag. 2019;22(4):362-8.

220 Klumpers LE, Thacker DL. A brief background on cannabis: from plant to medical indications. J AOAC Int. 2019;102(2):41220.

221 Mücke M, Weier M, Carter C, Copeland J, Degenhardt L, Cuhls H, et al. Systematic review and meta-analysis of cannabinoids in palliative medicine. J Cachexia Sarcopenia Muscle. 2018;9(2):220-34.

222 Hande K. Cannabidiol: the need for more information about its potential benefits and side effects. Clin J Oncol Nurs. 2019;23(2): 131-4.

223 Häuser W, Petzke F, Fitzcharles MA. Efficacy, tolerability and safety of cannabisbased medicines for chronic pain management: an overview of systematic reviews. Eur J Pain. 2018;22(3):455-70.

224 Gouveia DN, Guimarães AG, Santos WBDR, Quintans-Júnior LJ. Natural products as a perspective for cancer pain management: a systematic review. Phytomedicine. 2019;58: 152766.

225 Lichtman AH, Lux EA, McQuade R, Rossetti S, Sanchez R, Sun W, et al. Results of a double-blind, randomized, placebo-controlled study of nabiximols oromucosal spray as adjunctive therapy in advanced cancer patients with chronic uncontrolled pain. J Pain Symptom Manage. 2018 Feb;55(2): 179-88.e1.

226 Mücke M, Phillips T, Radbruch L, Petzke F, Häuser W. Cannabis-based medicines for chronic neuropathic pain in adults. Cochrane Database Syst Rev. 2018 Mar 7;3(3): CD012182.

227 Bellnier T, Brown GW, Ortega TR. Preliminary evaluation of the efficacy, safety, and costs associated with the treatment of chronic pain with medical cannabis. Ment Health Clin. 2018;8(3):110-5.

228 Crowley K, de Vries ST, Moreno-Sanz G. Self-reported effectiveness and safety of trokie((R)) lozenges: a standardized formulation for the buccal delivery of cannabis extracts. Front Neurosci. 2018;12:564.

229 Mbachi C, Attar B, Wang Y, Paintsil I, Mba B, Fugar S, et al. Association between cannabis use and complications related to Crohn's disease: a retrospective cohort study. Dig Dis Sci. 2019;64(10):2939-44.
230 Pamplona FA, da Silva LR, Coan AC. Potential clinical benefits of CBD-rich cannabis extracts over purified CBD in treatment-resistant epilepsy: observational data metaanalysis. Front Neurol. 2018 Sep 12;9:759.

231 Montgomery L, Bagot K, Brown JL, Haeny $\mathrm{AM}$. The association between marijuana use and HIV continuum of care outcomes: a systematic review. Curr HIV/AIDS Rep. 2019; 16(1):17-28.

232 Gross IM, Hosek S, Richards MH, Fernandez MI. Predictors and profiles of antiretroviral therapy adherence among African American adolescents and young adult males living with HIV. AIDS Patient Care STDS. 2016;30(7):324-38.

233 Fu X, Wang Y, Wang C, Wu H, Li J, Li M, et al. A mixed treatment comparison on efficacy and safety of treatments for spasticity caused by multiple sclerosis: a systematic review and network meta-analysis. Clin Rehabil. 2018;32(6):713-21.

234 Walsh Z, Gonzalez R, Crosby K, MST, S Thiessen M, Bonn-Miller MO. Medical cannabis and mental health: a guided systematic review. Clin Psychol Rev. 2017;51:1529.

235 Wang J, Wang YL, Tong MT, Pan HM, Li D. Medical cannabinoids for cancer cachexia: a systematic review and meta-analysis. Biomed Res Int. 2019 Jun 23;2019:2864384.

236 Swarm RA, Paice JA, Anghelescu DL, Are M, Bruce JY, Buga S, et al. Adult cancer pain, version 3.2019, NCCN clinical practice guidelines in oncology. J Natl Compr Canc Netw. 2019;17(8):977-1007.

237 Gouveia DN, Guimarães AG, Santos WBDR, Quintans-Júnior LJ. Natural products as a perspective for cancer pain management: a systematic review. Phytomedicine. 2019;58: 152766.

238 Gaston TE, Bebin EM, Cutter GR, Ampah SB, Liu Y, Grayson LP, et al. Drug-drug interactions with cannabidiol (CBD) appear to have no effect on treatment response in an open-label Expanded Access Program. Epilepsy Behav. 2019;98:201-6.

239 Lorenz DR, Uno H, Wolinsky SM, Gabuzda D. Effect of marijuana smoking on pulmonary disease in HIV-infected and uninfected men: a longitudinal cohort study. EClinicalMedicine. 2019;7:55-64.

240 Gaston TE, Bebin EM, Cutter GR, Ampah SB, Liu Y, Grayson LP, et al. Drug-drug interactions with cannabidiol (CBD) appear to have no effect on treatment response in an open-label Expanded Access Program. Epilepsy Behav. 2019;98:201-6.

241 Aran A, Cassuto H, Lubotzky A, Wattad N, Hazan E. Brief report: cannabidiol-rich cannabis in children with autism spectrum disorder and severe behavioral problems-a retrospective feasibility study. J Autism Dev Disorders. 2019;49(3):1284-8.
242 Anderson SP, Zylla DM, McGriff DM, Arneson TJ. Impact of medical cannabis on patient-reported symptoms for patients with cancer enrolled in Minnesota's medical cannabis program. J Oncol Pract. 2019;15(7): E338-45.

243 Crowley K, de Vries ST, Moreno-Sanz G. Self-reported effectiveness and safety of Trokie ${ }^{\oplus}$ Lozenges: a standardized formulation for the buccal delivery of cannabis extracts. Front Neurosci. 2018 Aug 14;12:564.

244 Chang YD, Jung JW, Oberoi-Jassal R, Kim J, Rajasekhara S, Haas M, et al. Edmonton symptom assessment scale and clinical characteristics associated with cannabinoid use in oncology supportive care outpatients. J Natl Compr Canc Netw. 2019;17(9):105964.

245 Elliott DA, Nabavizadeh N, Romer JL, Chen Y, Holland JM. Medical marijuana use in head and neck squamous cell carcinoma patients treated with radiotherapy. Support Care Cancer. 2016;24(8):3517-24.

246 Vin-Raviv N, Akinyemiju T, Meng Q, Sakhuja S, Hayward R. Marijuana use and inpatient outcomes among hospitalized patients: analysis of the nationwide inpatient sample database. Cancer Med. 2017;6(1): $320-9$.

247 Kosiba JD, Mitzel LD, Zale EL, Zvolensky MJ, Ditre JW. A preliminary study of associations between discomfort intolerance, pain severity/interference, and frequency of cannabis use among individuals with chronic pain. Addiction Research \& Theory. 2020; 28(1):76-81.

248 Orr MF, Rogers AH, Shepherd JM, Buckner JD, Ditre JW, Bakhshaie J, et al. Is there a relationship between cannabis use problems, emotion dysregulation, and mental health problems among adults with chronic pain? Psychol Health Med. 2020 Jul;25:74255.

249 Cooke AC, Knight KR, Miaskowski C. Patients' and clinicians' perspectives of co-use of cannabis and opioids for chronic noncancer pain management in primary care. Int J Drug Policy. 2019;63:23-8.

250 Bachhuber M, Arnsten JH, Wurm G. Use of cannabis to relieve pain and promote sleep by customers at an adult use dispensary. J Psychoactive Drugs. 2019 Nov-Dec;51:4004.

251 Mbachi C, Attar B, Wang Y, Paintsil I, Mba B, Fugar S, et al. Association between cannabis use and complications related to Crohn's disease: a retrospective cohort study. Dig Dis Sci. 2019 Oct;64:2939-44.

252 Adams JW, Bryant KJ, Edelman EJ, Fiellin DA, Gaither JR, Gordon AJ, et al. Association of cannabis, stimulant, and alcohol use with mortality prognosis among HIV-infected men (vol 22, pg 1341, 2018). AIDS Behav. 2018;22(7):2382. 